Check for updates

Cite this: Nanoscale Adv., 2019, 1, 4729

\title{
Spontaneous selective deposition of iron oxide nanoparticles on graphite as model catalysts $\dagger$
}

\author{
Chathura de Alwis, ${ }^{a}$ Timothy R. Leftwich, (iD ${ }^{b}$ Pinaki Mukherjee, (D) ${ }^{b}$ Alex Denofre ${ }^{a}$ \\ and Kathryn A. Perrine (D)*a
}

Iron oxide nanomaterials participate in redox processes that give them ideal properties for their use as earth-abundant catalysts. Fabricating nanocatalysts for such applications requires detailed knowledge of the deposition and growth. We report the spontaneous deposition of iron oxide nanoparticles on HOPG in defect areas and on step edges from a metal precursor solution. To study the nucleation and growth of iron oxide nanoparticles, tailored defects were created on the surface of HOPG using various ion sources that serve as the target sites for iron oxide nucleation. After solution deposition and annealing, the iron oxide nanoparticles were found to nucleate and coalesce at $400{ }^{\circ} \mathrm{C}$. AFM revealed that the particles on the $\mathrm{sp}^{3}$ carbon sites enabled the nanoparticles to aggregate into larger particles. The iron oxide nanoparticles were characterized as having an $\mathrm{Fe}^{3+}$ oxidation state and two different oxygen species, $\mathrm{Fe}-\mathrm{O}$ and $\mathrm{Fe}-\mathrm{OH} / \mathrm{Fe}-\mathrm{OOH}$, as determined by XPS. STEM imaging and EDS mapping confirmed that the majority of the nanoparticles grown were converted to hematite after annealing at $400{ }^{\circ} \mathrm{C}$. A mechanism of spontaneous and selective deposition on the HOPG surface and transformation of the iron oxide nanoparticles is proposed. These results suggest a simple method for growing nanoparticles as a model catalyst.

Received 2nd August 2019

Accepted 24th September 2019

DOI: $10.1039 / c 9 n a 00472 f$

rsc.li/nanoscale-advances
The focus for next-generation heterogeneous catalysts is on rational design, where metal and metal oxide materials could be selectively grown in defined areas to control the placement and concentration of catalyst materials, while minimizing costs. ${ }^{24-27}$ For selective deposition by area activation, the selectivity greatly depends upon the interaction between the metal adsorbate and the surface sites. ${ }^{\mathbf{2 4 2 7}}$ Carbon supports are typically utilized due to their high thermal and mechanical stability, without surface metal support interactions. ${ }^{28-34}$ Since the discovery of graphene, ${ }^{35}$ various methods have been used to alter the top layers of the surface providing nucleation points on an otherwise chemically stable material. ${ }^{36-42}$ Defects on graphene and graphite (highly oriented pyrolytic graphite) surfaces have been used to create surface sites for further growth of metals, particularly using various sputtering and plasma methods. ${ }^{43-45}$ Reactions have been shown to occur at the step edges and used for nanowire growth. ${ }^{46-48}$

Metal seed sites could be used as a way to selectively deposit material using activated areas to plant nucleation sites for further growth assemblies of nanoparticles. Many groups have utilized physical vapor deposition via metal evaporation ${ }^{\mathbf{4 7 4 9 - 5 6}}$ or electrodeposition to deposit metal nanoparticles on carbon supports. ${ }^{57-59}$ Soluble metallic precursors have been used previously to deposit and reduce metal nanoparticles onto graphitic materials such as graphite, graphene and carbon

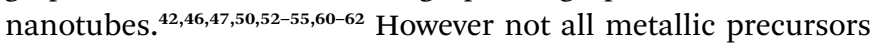
are known to nucleate at defects and grow metal nanoparticles

\footnotetext{
a Department of Chemistry, Michigan Technological University, Houghton, MI 49931 USA.E-mail: kaperrin@mtu.edu

${ }^{b}$ Department of Material Science \& Engineering, Michigan Technological University, Houghton, MI 49931, USA

$\dagger$ Electronic supplementary information (ESI) available. See DOI: 10.1039/c9na00472f
} 
spontaneously. Most chemical reactions occur via either reduction or functionalization, where the metal nanoparticles are covalently bound to the graphite surface. Only a few select studies report deposition without any hole scavengers, reducing agents or electrodeposition. ${ }^{63}$ Although defects in graphitic carbon materials are known to be highly reactive towards chemical vapor deposition precursors, soluble precursors typically do not spontaneously react with the surface without reduction of the metal ion through some other mechanism. There is some controversy over whether $\mathrm{Pt}$ or $\mathrm{Ru}$ precursors spontaneously react with the graphite surface..$^{63,64}$ Dai and coworkers found that Pt was spontaneously deposited at surface defects. Lemay and coworkers found that only with ethanol, which acts as a hole scavenger, do the precursors spontaneously react with the single walled nanotubes (SWNTs) without using a reducing agent. ${ }^{64}$ Other studies have found correlations between the reduction potential of the ions with carbon materials. ${ }^{65}$

In this study, evidence is presented for spontaneous selective deposition of iron oxide on highly oriented pyrolytic graphite (HOPG) using an iron chloride $\left(\mathrm{FeCl}_{2} \cdot 4 \mathrm{H}_{2} \mathrm{O}\right)$ precursor. Selective deposition was found to occur on the HOPG defects and step edges, which produced iron oxide nanoparticles without any additional chemical treatments. Iron oxide nanoparticles were found to nucleate and grow differently in the defect domain and the terrace domain. Annealing studies were carried out to understand how to control the selectivity in the defect areas, and also the phase of iron oxide. A mechanism is suggested for the deposition and conversion of iron hydroxides and oxyhydroxides into iron oxide upon annealing in air.

\section{Experimental methods}

\section{Sample preparation}

An aqueous $\mathrm{Fe}(\mathrm{II})$ chloride solution $\left(\mathrm{FeCl}_{2}(\mathrm{aq}), 0.5 \times 10^{-3} \mathrm{M}\right)$ was prepared by mixing $0.010 \mathrm{~g}$ of iron(II) chloride tetrahydrate, $\mathrm{FeCl}_{2} \cdot 4 \mathrm{H}_{2} \mathrm{O}$ (>99\%, Sigma-Aldrich), in $50.00 \mathrm{~mL}$ of ultra-pure water $(18 \mathrm{M} \Omega \mathrm{cm})$ in a clean volumetric flask. HOPG (ZYB grade, Mikromasch) was cut into $5 \mathrm{~mm} \times 10 \mathrm{~mm}$ samples. Both sides of these HOPG samples were exfoliated using adhesive tape until visibly smooth surfaces were obtained.

Defect formation. Various defects were created on the HOPG surface using either argon $\left(\mathrm{Ar}^{+}\right)$sputtering or a focused ion beam (FIB) to provide defects for nucleation sites. A Hitachi 2000 A FIB instrument was used to create tailored arrays of defects on HOPG using a $\mathrm{Ga}^{+}$beam energy of $30 \mathrm{kV}$ and a deceleration voltage of $8.8 \mathrm{kV}$ with a current of $3.2 \mu \mathrm{A}$. A striped pattern $12 \mu \mathrm{m} \times 28 \mu \mathrm{m}$ in size was created using a 50 $\mathrm{nm}$ aperture and $121 \mathrm{pA}$ beam current. A $20 \mathrm{~nm}$ aperture and 3 pA beam current were used to create $20 \mu \mathrm{m} \times 20 \mu \mathrm{m}$ arrays of square tailored defects (each square was $1 \mu \mathrm{m}^{2}$ in area). These pattern arrays were checked using a Hitachi field emission scanning electron microscope (FE-SEM) with a $10 \mathrm{kV}$ beam voltage and $10 \mathrm{~mA}$ beam current at a working distance of 12 $\mathrm{mm}$. The sputter rate was calculated using the amount of materials removed, by recording a height profile of $1 \mathrm{~nm}$ using atomic force microscopy (AFM) and the time to sputter the pattern, which was determined to be $1.68 \mathrm{~nm} \mathrm{~min}^{-1} . \mathrm{Ar}^{+}$sputtering was used to create a large density of defects across the entire surface for iron oxide nanoparticle nucleation on separate HOPG samples. A sputter gun was used to produce $\mathrm{Ar}^{+}$ions in a PHI 5800 X-ray photoelectron spectrometer (XPS) using a PHI 06-350 sputter gun. The $\mathrm{Ar}^{+}$ions bombarded the HOPG surface over a large area of $2 \mathrm{~mm} \times 2 \mathrm{~mm}$. The sample was rastered on the sample stage to sputter multiple areas of the surface. Twenty-four (4 rows of 6) different spots on the sample surface were sputtered by moving the sample with respect to the ion gun to sputter the entire $5 \mathrm{~mm} \times 10 \mathrm{~mm}$ sample area. A sputtering rate of $1.7 \mathrm{~nm} \mathrm{m^{-1 }}$ was used with a time of 1 minute per spot. The sputter rate was calibrated by sputtering a silicon oxide sample with a known oxide thickness of $100 \mathrm{~nm}$ (RBD Instruments). The extractor pressure was recorded as 15 $\mathrm{mPa}$ while the beam energy of the gun was $5 \mathrm{kV}$.

Deposition and growth of iron oxide nanoparticles. Iron oxide nanoparticles were grown by applying a few drops of $\mathrm{FeCl}_{2}(\mathrm{aq})$ solution using a clean glass Pasteur pipette to produce a droplet (using 5 drops from the pipette, a total of $0.14 \mathrm{~mL}$ ) to cover the majority of the HOPG surface. The samples were covered with a watch glass to prevent evaporation. After two hours, the HOPG samples were rinsed with approximately 50 $\mathrm{mL}$ of ultra-pure water $(18 \mathrm{M} \Omega \mathrm{cm})$ and dried in air. Then, the samples were either analyzed using the surface characterization techniques described below, or placed in a furnace oven for annealing studies.

The iron oxide nanoparticles supported on HOPG were annealed in a furnace oven at different temperatures $\left(100^{\circ} \mathrm{C}, 200\right.$ ${ }^{\circ} \mathrm{C}, 300{ }^{\circ} \mathrm{C}, 400{ }^{\circ} \mathrm{C}$ and $500{ }^{\circ} \mathrm{C}$ ) for 2 hours in air, inside a clean quartz tube. Prior to sample annealing, the quartz tube was cleaned with nitric acid, rinsed and pre-heated at $400{ }^{\circ} \mathrm{C}$ for 30 minutes. The sample was then placed in the quartz tube and annealed to measure the effect of diffusion of the iron oxide nanoparticles in the HOPG defect areas. After each temperature treatment, the sample was imaged under FE-SEM to observe the distribution of the iron oxide nanoparticles on the HOPG surface.

\section{Surface characterization}

Field emission scanning electron microscopy (FE-SEM). All the samples were imaged using a Hitachi S-4700 cold field emission high resolution FE-SEM instrument, which was kept at a high vacuum of around $10^{-8}$ torr. Samples were imaged at $10 \mathrm{kV}$ accelerating voltage using a beam current of $10 \mu \mathrm{A}$ and a working distance of $12 \mathrm{~mm}$. The samples were mounted on a circular standard sample holder and clamped using copper clips, which minimized surface charging. The surface of freshly cleaved HOPG was first imaged to use it as a reference image. Then both FIB and $\mathrm{Ar}^{+}$sputtered samples were imaged before applying the $\mathrm{FeCl}_{2}(\mathrm{aq})$ solution. The HOPG samples were imaged before and after the chemical treatment to check the surface distribution of iron oxides before annealing. After each annealing step at a specified temperature, the samples were reimaged to observe the changes of thermal migration of iron oxide nanoparticles at temperatures up to $500{ }^{\circ} \mathrm{C}$, the temperature at which HOPG is known to begin oxidizing in air. ${ }^{66}$ 
Atomic force microscopy (AFM). AFM images were collected after iron oxide nanoparticles were deposited on the HOPG surface at room temperature and after HOPG was annealed at $400{ }^{\circ} \mathrm{C}$. AFM images were collected on an Asylum MFP3 instrument. Aluminum coated silicon cantilevers (BudgetSensors) with a force constant of $40 \mathrm{~N} \mathrm{~m}^{-1}$ and a resonant frequency of $300 \mathrm{kHz}$ were used to collect images using 256 points per line. AFM images were post-processed using a $3^{\text {rd }}$ order flattening. The nanoparticle dimensions were estimated by counting all particles larger than $1 \mathrm{~nm}$ in height. The root mean squared (RMS) value was measured as an estimation of the surface roughness for both the terrace and defect regions on the samples.

X-ray photoelectron spectroscopy (XPS). XPS was performed using a PHI 5800 to analyze the elemental composition and oxidation state of surface species of the iron oxide nanoparticles grown on the HOPG surface. The C1s, O1s, Cl2p, Fe2p and survey spectra were collected using a Mg X-ray source and an $800 \mu \mathrm{m}$ diameter detector aperture. The distance between the sample and the X-ray source was adjusted to increase the signal of the C1s graphitic peak at $284.6 \mathrm{eV}$. Survey spectra were collected using a pass energy of $187.85 \mathrm{eV}$, a resolution of $0.8 \mathrm{eV}$ per step and a dwell time of $20 \mathrm{~ms}$ per step. High resolution spectra were collected using a pass energy of $23.50 \mathrm{eV}$, a resolution of $0.1 \mathrm{eV}$ per step and a dwell time of $100 \mathrm{~ms}$ per step. A Shirley background was used to deconvolute the Fe2p and O1s regions using $100 \%$ Gaussian peak fits. The Tougaard background subtraction was used for the C1s region. ${ }^{67}$ The C1s peaks were fitted with Doniach-Šunjić $(0.02,300)$ asymmetric line shapes for the $\mathrm{sp}^{2}$ carbon peaks $\mathrm{s}^{68-70}$ and the remaining peaks were fitted using $100 \%$ Gaussian line shapes. Charge correction of all the regions was done with respect to the graphitic C1s peak at a binding energy of $284.6 \mathrm{eV}$.

Scanning transmission electron microscopy (STEM). Graphene (6-8 layers, graphene thickness $2.1-2.8 \mathrm{~nm}$ ) on lacey carbon on a 300 mesh copper TEM grid (Electron Microscopy Sciences, product number 6GLC300Cu) was used as a substitute for HOPG (see Fig. S1 in the ESI†). The $\mathrm{FeCl}_{2}(\mathrm{aq})$ solution was deposited on the graphene coated grid and annealed at $400{ }^{\circ} \mathrm{C}$, as described above to obtain a sample with iron oxide nanoparticles grown thin enough for STEM imaging. STEM imaging and energy dispersive X-ray spectroscopy (EDS) mapping were used to measure the phase and composition of iron oxide nanoparticles after annealing and to confirm if the deposition was preferential at the defect sites of graphite. A FEI Titan Themis aberration corrected scanning transmission electron microscope was used to obtain atomically resolved electron images and EDS maps of the iron oxide nanoparticles on the graphene coated TEM grid. The microscope was operated at 200 $\mathrm{kV}$ using a point resolution of the aberration corrected STEM mode of $0.08 \mathrm{~nm}$. The microscope was equipped with a SuperX ${ }^{\mathrm{TM}} \mathrm{X}$-ray detector, which is composed of 4 detectors for fast X-ray mapping in STEM mode. The EDS mapping of the sample was performed on specific particles with an average beam current of $100 \mathrm{pA}$. The size of EDS maps was $512 \times 512$ pixels and the dwell time that was used for collecting the signal was $20 \mu$ s per pixel. All EDS maps were generated by summing up 10 frames. Velox software was used to perform drift correction during data collection and subsequent data analysis. The experimental diffraction patterns were indexed using Jems electron microscopy simulation software. ${ }^{71}$ We used crystallographic data available in the JCPDS database (JCPDS card number 01-076-4579 for $\alpha-\mathrm{Fe}_{2} \mathrm{O}_{3}$ and number 00-019-0629 for $\mathrm{Fe}_{3} \mathrm{O}_{4}$ ) in order to identify the type of iron oxide on the graphene grid. The post-processing of atomically resolved images was performed using Microimage and ImageJ software.

\section{Results and discussion}

\section{Spontaneous and selective deposition at defects}

FE-SEM was used as the first analysis method to image the distribution of iron oxide nanoparticles on the HOPG surface. The HOPG surface typically consists only of a terrace area with $\mathrm{sp}^{2}$ hybridized carbon and defect sites at the step edges between sheets of graphene. ${ }^{72-74} \mathrm{Fig}$. 1A shows a defect step edge on a flat HOPG surface. This can be compared to Fig. 1B, where nanoparticles were grown on the HOPG step edges from exposure to the $\mathrm{FeCl}_{2}(\mathrm{aq})$ solution. This result suggests that the iron oxide is spontaneously adsorbed on the step edges on the HOPG surface without any additional treatment. This is surprising as aqueous metal precursor solutions typically require reducing agents or electrodeposition to deposit metals on the HOPG surface. It was found for $\mathrm{AgNO}_{3}$ without any reduction treatments, $\mathrm{Ag}$ is deposited and aggregates to form large $\mu \mathrm{m}$ sized Ag clusters after deposition..$^{53,75}$ Other studies found that $\mathrm{Na}_{2} \mathrm{PtCl}_{6}$ or $\mathrm{HAuCl}_{4}$ precursors spontaneously react selectively with defects on SWCNTs. ${ }^{63}$ Here we observe spontaneous, selective deposition of iron oxide nanoparticles starting with an aqueous $\mathrm{FeCl}_{2}(\mathrm{aq})$ solution.

To create a higher density of iron oxide nanoparticles, the HOPG surface was $\mathrm{Ar}^{+}$sputtered prior to exposure of the $\mathrm{FeCl}_{2}(-$ aq) solution to create multiple defects for iron oxide nucleation, as shown in Fig. 1C. Additionally, tailored arrays of $1 \mu \mathrm{m}^{2}$ defects, in Fig. 1D, were created using the FIB with $\mathrm{Ga}^{+}$to generate uniform nucleation sites and observe deposition of the iron oxide nanoparticles. The defect patterns on the FIB sputtered samples are limited to specific small regions $(20 \mu \mathrm{m} \times 20 \mu \mathrm{m}$ arrays $)$ on the HOPG surface. After a two-hour chemical treatment with the $\mathrm{FeCl}_{2}(\mathrm{aq})$ solution, the iron oxide nanoparticles are found deposit in the square defect regions on HOPG at room temperature (Fig. 1E and F). The iron oxide nanoparticles primarily nucleated on the defect sites on the HOPG surface with some deposition of nanoparticles on the terrace regions. The relative concentration of these particles is somewhat higher in the defect areas than on the terrace, as expected. The magnified area in Fig. $1 \mathrm{~F}$ indicates that iron oxide nanoparticles have nucleated both on the step edges and in the square defect areas.

There are some differences when using $\mathrm{Ga}^{+}$and $\mathrm{Ar}^{+}$to form defects, thus causing amorphization in the HOPG surface. FIB sputtering with $\mathrm{Ga}^{+}$was used to create defects at a sputtering rate of $1.68 \mathrm{~nm} \mathrm{~min}{ }^{-1}$, for a $20 \mu \mathrm{m} \times 20 \mu \mathrm{m}$ tailored array of uniform defects, compared to sputtering with $\mathrm{Ar}^{+}$at a rate of 1.7 $\mathrm{nm} \mathrm{min}{ }^{-1}$, for a $2 \mathrm{~mm} \times 2 \mathrm{~mm}$ area. AFM images were collected 


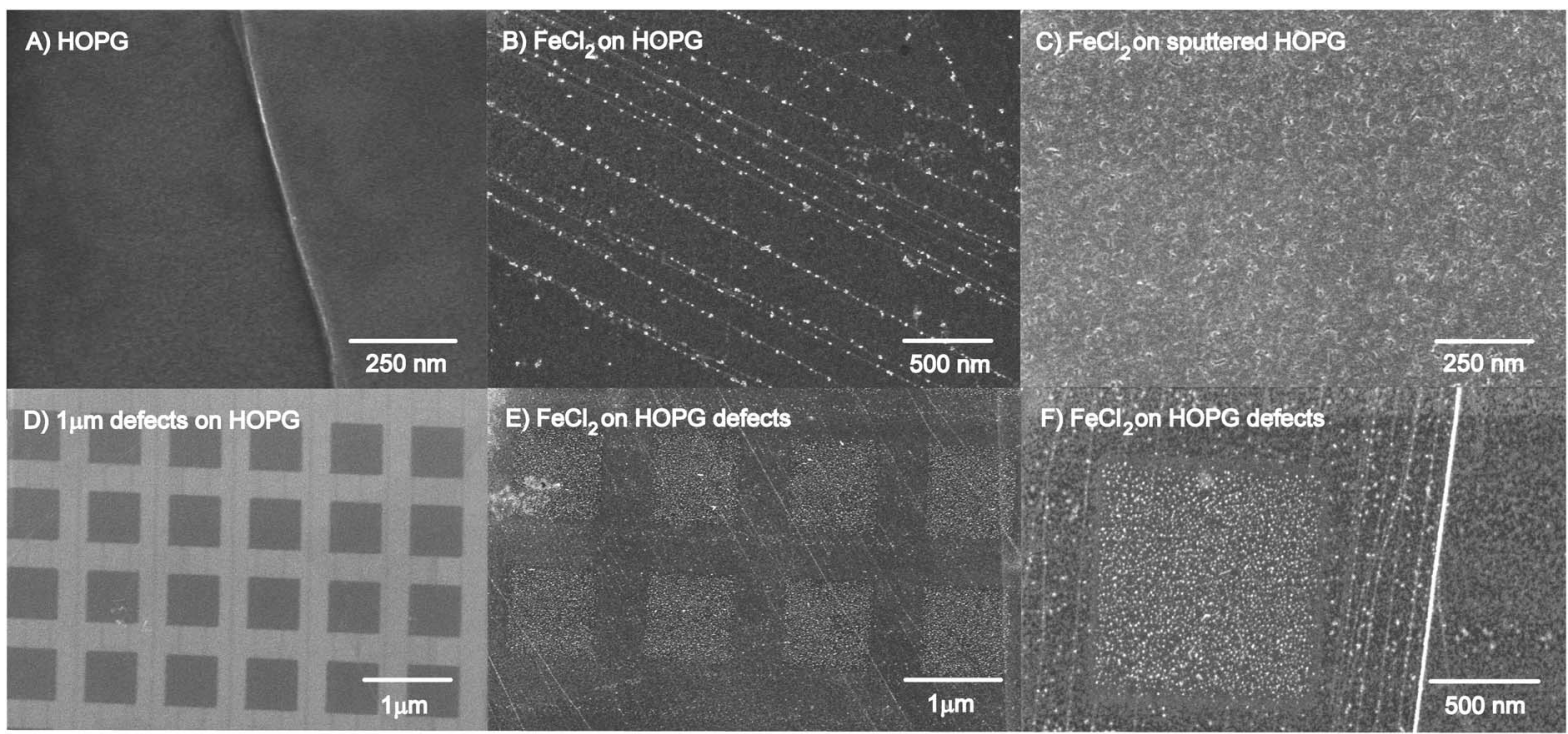

Fig. 1 FESEM images comparing both cleaved HOPG and FIB HOPG defect areas before and after exposure to $\mathrm{FeCl}_{2}(\mathrm{aq})$ : (A) HOPG, (B) iron oxide nanoparticles grown on HOPG, (C) iron oxide nanoparticles grown on $\mathrm{Ar}^{+}$sputtered HOPG, (D) FIB HOPG, (E) iron oxide nanoparticles grown on FIB defects on HOPG, and (F) higher magnification image of $(E)$ - note: the white line is iron oxide nanoparticles grown on a step edge across the image.

for each sample with average root mean squared (RMS) values as a measure of surface roughness (shown in Fig. S2 in the ESI†). The RMS values for the $\mathrm{Ar}^{+}$and $\mathrm{Ga}^{+}$sputtered samples were shown to increase, with $\mathrm{Ga}^{+}$having the highest average RMS value, due to the higher energy of sputtering (30 keV compared to $5.0 \mathrm{keV}$ from $\mathrm{Ar}^{+}$). Embedded argon was observed after $\mathrm{Ar}^{+}$sputtering but after $\mathrm{Ga}^{+}$sputtering, no embedded $\mathrm{Ga}^{+}$ was detected with XPS (not shown). These differences could also be attributed to the deceleration of the Ga ion beam and the short dwell time compared to manual stage adjustment during the argon sputtering.

$\mathrm{Ar}^{+}$sputtering has been known to produce amorphization, thus converting the HOPG hybridized graphitic sheets into aliphatic carbon and producing dangling carbon bonds for further reaction. ${ }^{76}$ For this study, iron oxide nanoparticles were shown to grow on the step edge defect sites on unsputtered HOPG. Therefore, it was expected that $\mathrm{Ar}^{+}$sputtering created a wide array of aliphatic carbon producing more nucleation sites for nanoparticle growth. Another study investigated HOPG implanted with $\mathrm{N}$ and Ar atoms separately. ${ }^{77}$ Defects were found on HOPG to serve as anchoring sites for the oxygen reduction reaction, produced from $\mathrm{N}^{+}$and $\mathrm{Ar}^{+}$sputtering, forming $\mathrm{C}-\mathrm{N}$ species on the HOPG surface. Annealing at $500{ }^{\circ} \mathrm{C}$ in UHV was found to restore the HOPG surface. In air, studies have shown that annealing in oxygen is found to burn the surface beginning at $500{ }^{\circ} \mathrm{C} .3^{39,57,58,66,78}$ In this study, etching was found to occur at these temperatures, as discussed next.

\section{Thermal annealing of nanoparticles}

After deposition, the samples were annealed in air to test if the iron oxide nanoparticles would coalesce into larger particles and increase the density of nanoparticles in the defect areas.
FESEM images were collected after each annealing treatment of the same sample, as shown in Fig. 2. Other defect patterns were created using the FIB, to easily track the effect of iron oxide nanoparticle from diffusion and growth in the defect areas. FESEM images in Fig. 2 and 3 show that the majority of the iron oxide nanoparticles are deposited in the defect areas at room temperature (Fig. 2A). After annealing at $100^{\circ} \mathrm{C}$ (Fig. 2B), $200^{\circ} \mathrm{C}$ (Fig. 2C) and $300^{\circ} \mathrm{C}$ (Fig. 2D and G), no changes are observed in the FESEM images. However, after annealing at $400{ }^{\circ} \mathrm{C}$, the iron oxide nanoparticles became larger and brighter in the defect areas (Fig. 2E and H). A higher magnification image (Fig. 2H) of the particles suggests that either holes are etched into the defect region of the graphite surface or larger shell-like nanoparticles are formed. No clear changes of the nanoparticles in the terrace region are observed. This shows that there are two different domains of nanoparticles present on the defected HOPG surface: on the terrace region and in the defect areas.

After further annealing at $500{ }^{\circ} \mathrm{C}$ (Fig. $2 \mathrm{~F}$ and $3 \mathrm{~F}$ ) the iron oxide nanoparticles agglomerate and the HOPG surface appears to etch from surface oxidation beginning from the defect edge sites, forming channels in the HOPG surface (see more images in Fig. S2, ESI $\dagger)^{58,66,79,80}$ The bare HOPG surface has been observed previously to etch by annealing in air, beginning also at $500{ }^{\circ} \mathrm{C}$, but the primary surface oxidation was found to occur at $650{ }^{\circ} \mathrm{C} .{ }^{66}$ The defect regions have been shown to be affected by oxidation at lower temperatures. ${ }^{66}$ It may be suggested that the iron oxide nanoparticles contribute to the oxidation of the HOPG surface, thus catalyzing the etching rate on the HOPG surface, as also observed for Ni nanoparticles ${ }^{80}$ and other noble metals. ${ }^{78,81}$ These details are highlighted below.

The uniform square $\left(1 \mu \mathrm{m}^{2}\right)$ defect areas, created by the FIB instrument, were also imaged after annealing treatments, as shown in Fig. 3. The FIB defects are limited to a very small area 


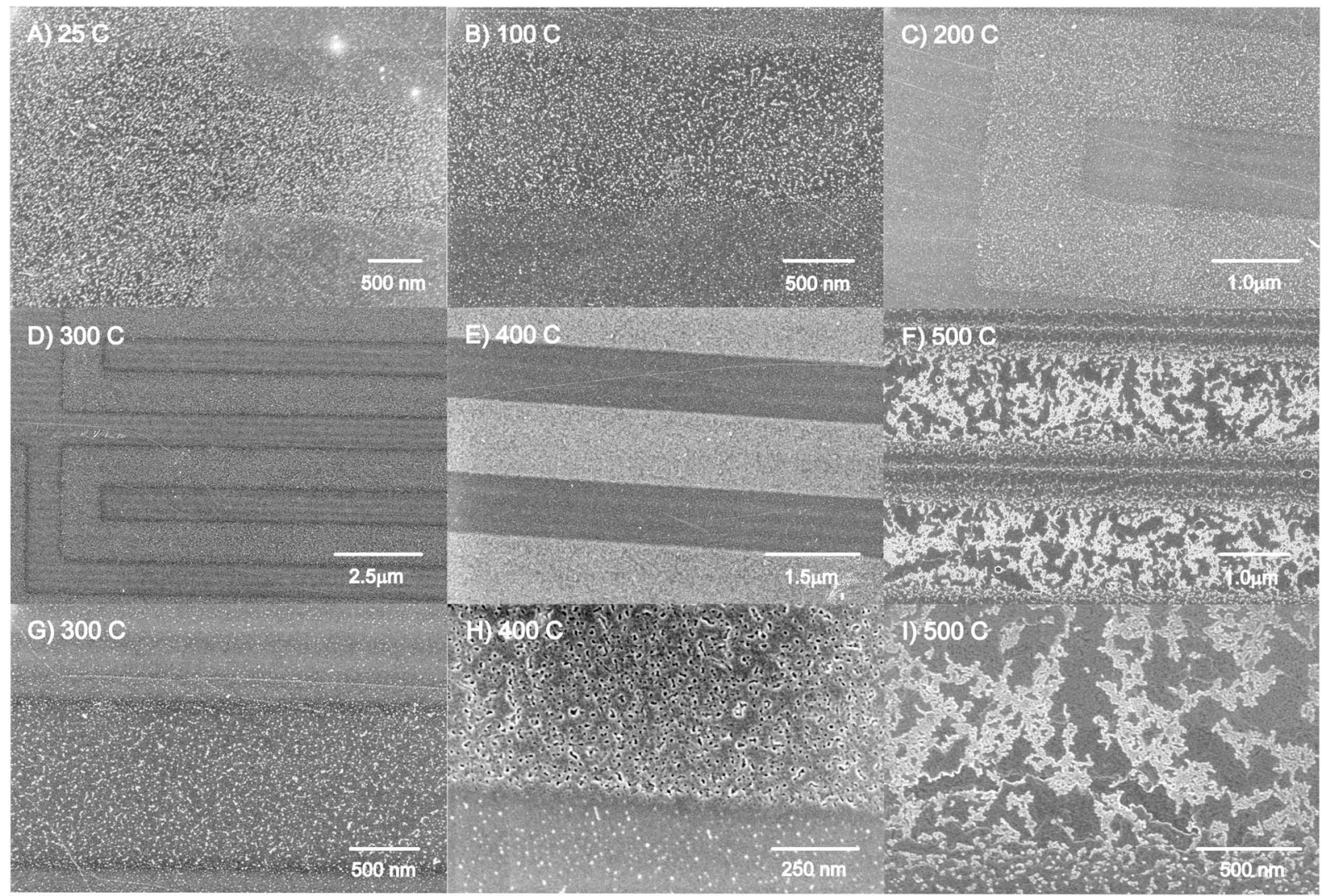

Fig. 2 FESEM images of iron oxide nanoparticles deposited on $\mathrm{HOPG}$ at (A) $25^{\circ} \mathrm{C}$ and annealed in air, sequentially at (B) $100{ }^{\circ} \mathrm{C},(\mathrm{C}) 200{ }^{\circ} \mathrm{C},(\mathrm{D})$ $300^{\circ} \mathrm{C},(\mathrm{E}) 400^{\circ} \mathrm{C}$ and $(\mathrm{F}) 500^{\circ} \mathrm{C}$. Images (G), (H) and (I) are higher magnification images in regions of Figures (D), (E), and (F), respectively.

on the HOPG surface, enabling us to track the changes of the iron oxide nanoparticles in the defect regions. The iron oxide nanoparticles are formed at defect sites on the HOPG surface (Fig. 3A). The images (Fig. 3B to Fig. 3F) depict the results of the iron oxide nanoparticles on HOPG after annealing from $100^{\circ} \mathrm{C}$ to $500^{\circ} \mathrm{C}$. As the temperature of the annealing step increases from $100{ }^{\circ} \mathrm{C}$ to $400{ }^{\circ} \mathrm{C}$, the iron oxide nanoparticles appear to migrate and coalesce into larger nanoparticles in the defect region (Fig. 3E). No apparent changes are observed for the nanoparticles on the terrace region with increasing annealing temperature.

Images in Fig. 3 and S3† clearly show the creation of large channels beginning at the edges of the defect areas, created originally by the FIB. The square patterns are widened and some of the FIB lines produce $200-300 \mathrm{~nm}$ channels from the edges of the square area (see Fig. S3†), occurring from air oxidation of the HOPG surface. The bright regions in Fig. $3 \mathrm{~F}$ are iron oxide nanoparticles that have either migrated to the edge defects of the square area or coalesced in the area. This indicates that the higher the temperature, the higher the thermal energy that facilitates the diffusion of iron oxide nanoparticles into the defect areas and by $500{ }^{\circ} \mathrm{C}$, begins to etch the HOPG surface.

Since we observed two different domains of nanoparticles after annealing at $400{ }^{\circ} \mathrm{C}$, the RMS values, a measure of the surface roughness, and particle size distributions were analyzed

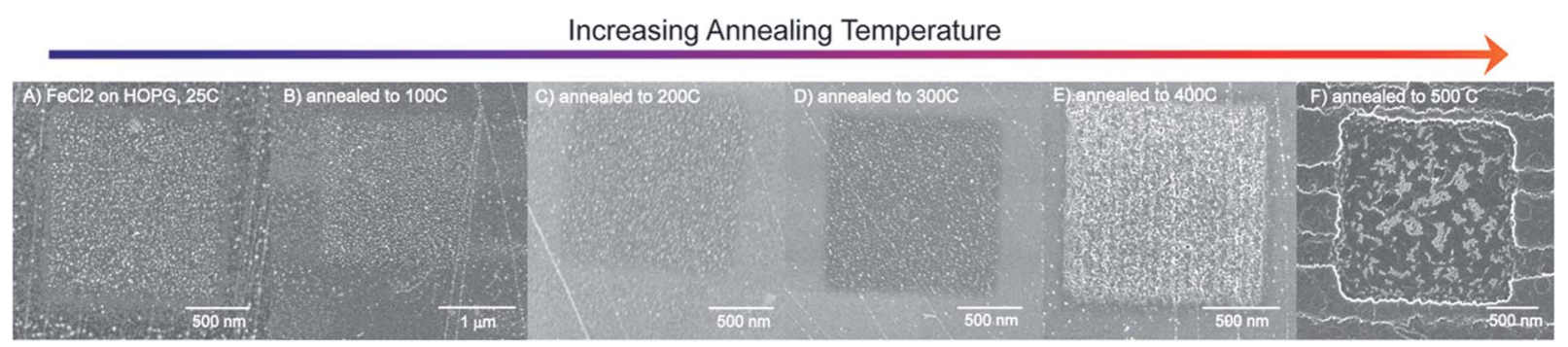

Fig. 3 FESEM images of the annealing profile of iron oxide nanoparticles on $\mathrm{HOPG}$ annealed to (A) $25^{\circ} \mathrm{C},(\mathrm{B}) 100^{\circ} \mathrm{C},(\mathrm{C}) 200{ }^{\circ} \mathrm{C},(\mathrm{D}) 300^{\circ} \mathrm{C},(\mathrm{E})$ $400{ }^{\circ} \mathrm{C}$ and (F) $500{ }^{\circ} \mathrm{C}$. Iron oxide nanoparticles are shown to coalesce in defect sites of an FIB sputtered HOPG sample by $400{ }^{\circ} \mathrm{C}$. After annealing to $500^{\circ} \mathrm{C}$, the HOPG surface begins to oxidize forming large channels, beginning at the defect $\left(\mathrm{sp}^{3}\right)$ sites. 
using AFM. These images are compared to FESEM images of various magnifications in Fig. 4. Iron oxide nanoparticles were observed to nucleate on two different domains of the HOPG surface, the terrace region and the defect region. In Fig. 4, the black arrows point to the defect region and reveal a film-like morphology and the white arrows point to the terrace region of the HOPG surface.

In the defect region, it appears that larger particles were formed and they have a core-shell-like structure. The FESEM images in Fig. 4 show a white halo around the dark particles at high magnification. The phase images, shown to the right of the AFM images, suggest that the nanoparticles grown inside the defect areas are composed of a hard material compared to the soft HOPG surface. This is evident from the difference in phase angle, a smaller degree for the iron oxide nanoparticles compared to the larger phase degree from the HOPG surface. This indicates that the features in the height image have a higher hardness characteristic of that of a metal structure on the soft carbon surface, showing that the iron oxide nanoparticles have grown on the defect sites, in agreement with the FESEM images. An AFM height profile plot compares the nanoparticles in the defect region with those on the terrace regions, suggesting that the particles are similar $(4-5 \mathrm{~nm})$ in height in both regions. An RMS value of $0.96 \mathrm{~nm}$ was found for the defect region, in contrast to the RMS value of $1.53 \mathrm{~nm}$ for the terrace region. This is reflected in the smaller distribution of nanoparticles, where larger diameter particles are grown and well dispersed across the defect region on the HOPG surface.

On the terrace region, the particle size distributions were analyzed before and after annealing (shown in Fig. 5). Here, the RMS value has decreased from $2.0 \mathrm{~nm}$ to $1.61 \mathrm{~nm}$ after annealing. On the terrace region, the nanoparticles have not coalesced significantly, but do become a less tight size distribution. After deposition at the defect step edges, the nanoparticles appear to remain trapped in a stable binding site on the HOPG step edge. We attribute these observations to the thermal energy needed for nanoparticle agglomeration and interactions with the surface. In the defect region, most of the surface is composed of $\mathrm{sp}^{3}$ carbon, which is not as stable as aliphatic carbon at high temperatures. Upon annealing, the nanoparticles on the $\mathrm{sp}^{3}$ carbon sites in the defect areas acquire enough thermal energy to migrate and coalesce into larger particles. On the terrace region, mainly comprised
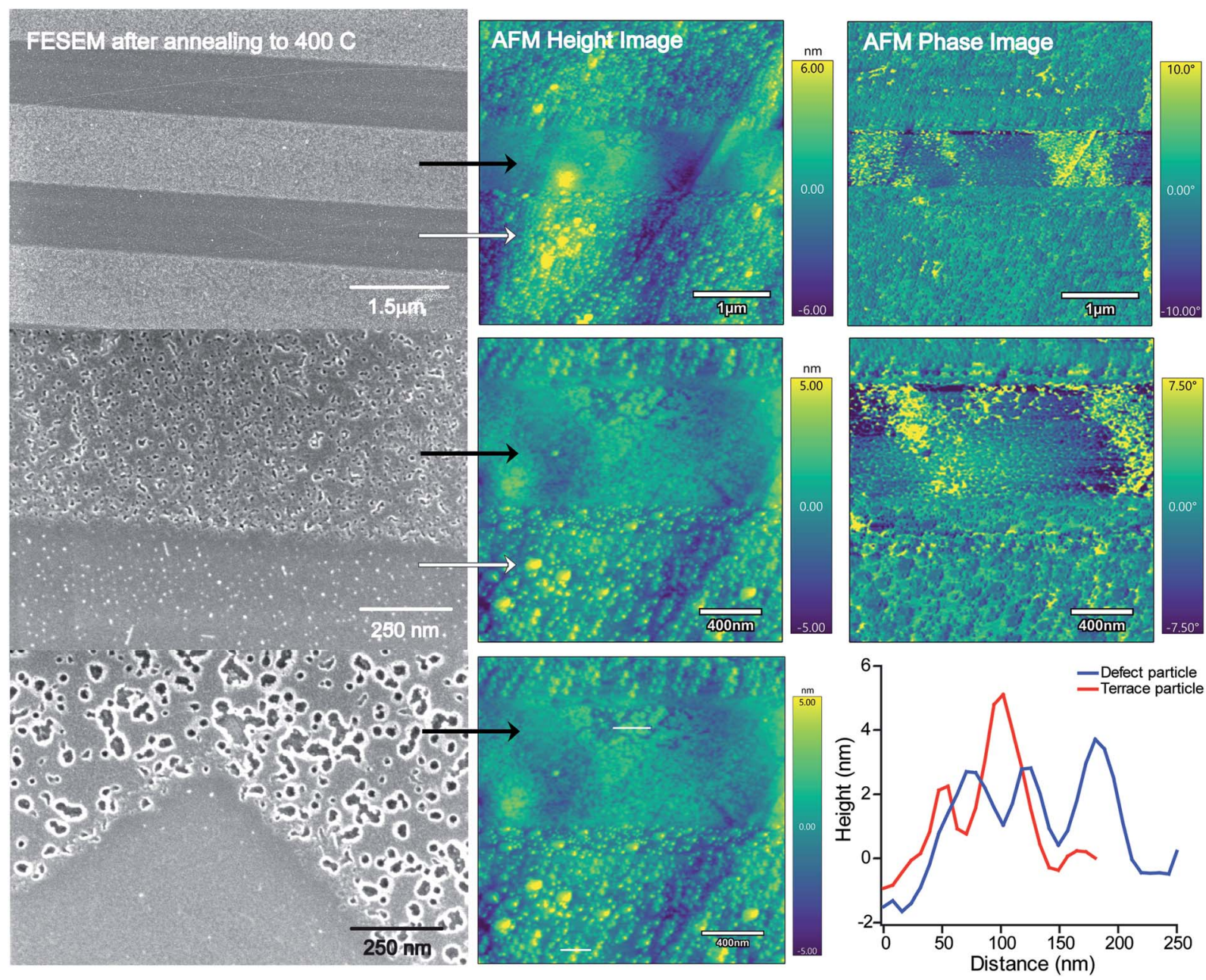

Fig. 4 A comparison of FESEM images with AFM height and phase images of iron oxide nanoparticles on $\mathrm{HOPG}$ after annealing at $400^{\circ} \mathrm{C}$. Arrows point to the two different domains of iron oxide nanoparticles: (black) the defect region and (white) the terrace region. Two height profiles of particles in the defect area (blue) and the terrace area (red) are shown. 

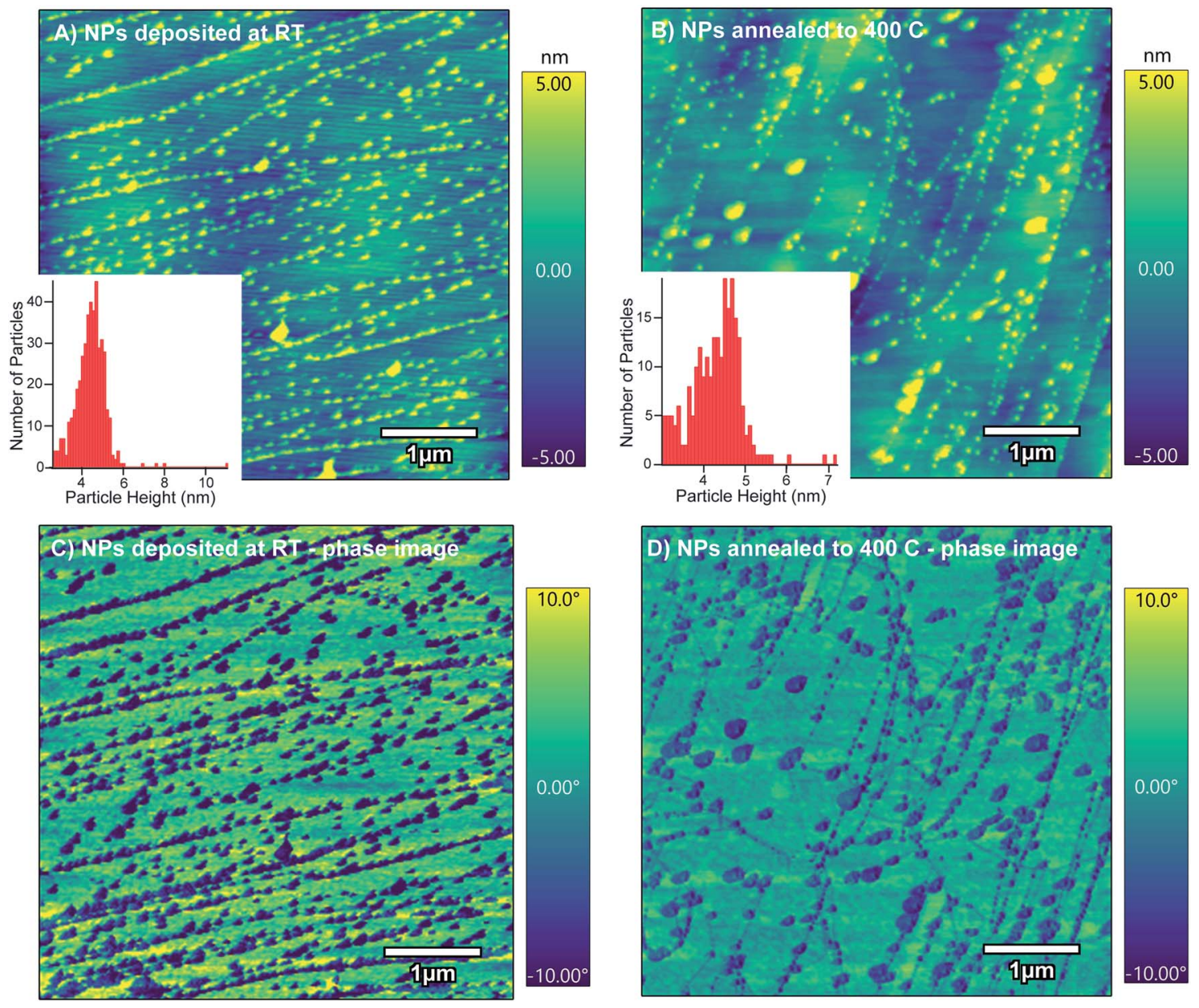

Fig. 5 AFM height and particle size distributions of iron oxide nanoparticles grown in the HOPG terrace region (A) at room temperature (RT) and (B) after annealing at $400^{\circ} \mathrm{C}$. The AFM phase images are shown below each height image at (C) RT and (D) after annealing at $400{ }^{\circ} \mathrm{C}$.

of $\mathrm{sp}^{2}$ carbon with $\mathrm{sp}^{3}$ carbon at the step edges, the iron oxide nanoparticles that are in a fixed binding site do not move upon annealing at $400{ }^{\circ} \mathrm{C}$. Here the nanoparticles may be restricted to the HOPG step edges, where only the $\mathrm{sp}^{3}$ carbon sites are present and nanoparticle diffusion occurs. This could explain why the particles inside the defect area are able to migrate and coalesce compared to the nanoparticles on the step edges of the HOPG surface.

Some of the results presented in the images (Fig. 2-5) above can be explained by the similar behavior of metal deposition on graphite surfaces. The metal diffusion phenomenon has been observed for other metals $(\mathrm{Cu}, \mathrm{Ru}$, and Dy) that were evaporated onto the HOPG surface. ${ }^{82-89}$ At substantially higher temperatures above $800{ }^{\circ} \mathrm{C}$ in vacuum (without oxygen), the metals were shown to diffuse under the graphene sheets beginning at the defects. There, the metal atoms form boat-like islands, and graphite will reform the moire patterns on top of the metal boats. We attempted STM in our studies with iron, but were unsuccessful in obtaining similar features under our annealing conditions. In our study, oxidation occurs in air at $500{ }^{\circ} \mathrm{C}$ along with etching of the defect patterns where channels are created in the graphite surface. Simultaneous oxidative etching of
HOPG occurs with the coalescence of the iron oxide nanoparticles. A similar etching observation has been made for evaporated Ni particles that formed similar channels, through a catalytic hydrogenation etching mechanism, also at $500^{\circ} \mathrm{C}$, in hydrogen gas followed by subsequent annealing at $900{ }^{\circ} \mathrm{C} .{ }^{80} \mathrm{Our}$ observations here suggest that if catalytic etching occurs in air by the iron oxide nanoparticles, the onset begins between 400 ${ }^{\circ} \mathrm{C}$ and $500{ }^{\circ} \mathrm{C}$.

Post-annealing of sputtered graphite surfaces has been known to stabilize transition metal nanoparticles at different temperatures. $\mathrm{Ag}$ nanoparticles deposited by electron beam deposition on HOPG were found to deposit in the first few layers of HOPG. Annealing the unsputtered HOPG above $150{ }^{\circ} \mathrm{C}$ allowed for the $\mathrm{Ag}$ nanoparticles to sinter; however, annealing after sputtering the HOPG surface enabled the stabilization of the $\mathrm{Ag}$ nanoparticles. This could be due to the catalytic effect of $\mathrm{Ag}$, thus inducing surface reconstruction of the moire lattice pattern. ${ }^{78}$ In the presence of ethylene and oxygen, surface etching was shown to occur at a much lower temperature of 250 ${ }^{\circ} \mathrm{C}$ compared to annealing in air, where the etching was found to begin at $500{ }^{\circ} \mathrm{C} .{ }^{66}$ Another study investigated noble metal coreshell nanoparticles on $\mathrm{Ar}^{+}$sputtered HOPG. It was determined 
that Au nanoparticles with a uniform (4-7 nm) size distribution could be grown on sputtered HOPG after annealing at $300{ }^{\circ} \mathrm{C}$. These studies agree with our results that sputtering can anchor metallic nanoparticles to graphitic surfaces and may provide stabilization. Annealing of the $\mathrm{Au}$ nanoparticles at $300{ }^{\circ} \mathrm{C}$ allowed them to coalesce to a narrow size distribution..$^{\mathbf{8 1}}$ Other nanoparticles with narrow size distributions have been grown using metal evaporation on pre-annealed HOPG, which allows

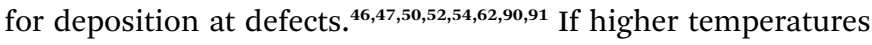
are used to anneal the graphite, the nanoparticles are able to diffuse to a defect site and tunnel under the graphite sheets producing metal islands, as observed in the STM studies. ${ }^{\mathbf{8 2 , 8 4 - 8 6}}$ Although this was not observed in our studies, further investigation of other transition metal nanoparticles on graphitic materials may isolate differences and trends in effects from annealing. In this study, it is apparent, from Fig. 2-5, that the iron oxide nanoparticles in the defects migrate during annealing in air at modest temperatures. This is possibly due to the weak interactions from physisorption between iron oxide nanoparticles and the $\mathrm{sp}^{3}$ defects on the HOPG surface, resulting in a domain of larger particles. Next, we examine the elemental composition and oxidation states of iron oxide nanoparticles using XPS.

\section{XPS analysis}

XPS was used to measure the oxidation states of the iron oxide nanoparticles grown on HOPG and $\mathrm{Ar}^{+}$sputtered HOPG before and after annealing at $400{ }^{\circ} \mathrm{C}$. The $\mathrm{C} 1 \mathrm{~s}, \mathrm{O} 1 \mathrm{~s}, \mathrm{Cl} 2 \mathrm{p}$ and $\mathrm{Fe} 2 \mathrm{p}$ regions were examined. The HOPG surface was sputtered with $\mathrm{Ar}^{+}$to create a high density of small defect sites, thus allowing for a high distribution of nucleation points for iron oxide nanoparticle deposition. This increase in density of the iron oxide nanoparticles provided a sufficient signal to characterize the oxidation state of iron oxide by XPS. Fig. 6 compares the Fe2p and
O1s regions for the HOPG and the sputtered HOPG surfaces exposed to $\mathrm{FeCl}_{2}(\mathrm{aq})$ before and after annealing at $400{ }^{\circ} \mathrm{C}$. The spectra in the Fe2p region (Fig. 6A) show $\mathrm{Fe}-\mathrm{O}$ at an $\mathrm{Fe}_{2} \mathrm{p}_{3 / 2}$ binding energy of $711.4 \mathrm{eV}$ after deposition of the iron oxide nanoparticles on both HOPG and the sputtered HOPG at room temperature. The peak at $711.4 \mathrm{eV}$ is assigned to the $\mathrm{Fe}^{3+}$ oxidation state, in agreement with previous studies of evaporated Fe metal on HOPG. ${ }^{92,93}$ These binding energies are higher by $0.5-1$ eV compared to single crystal $\alpha-\mathrm{Fe}_{2} \mathrm{O}_{3}(0001)$ (hematite) at 710.9 $\mathrm{eV}$ and $\mathrm{Fe}_{3} \mathrm{O}_{4}(001)$ (magnetite) at $710.4 \mathrm{eV}$, owing to the oxidation of the particles from exposure to ambient conditions. ${ }^{\mathbf{9 2 , 9 4}}$ Apart from the $\mathrm{Fe}-\mathrm{O}$ peak in the $\mathrm{Fe} 2 \mathrm{p}_{3 / 2}$ and $\mathrm{Fe} 2 \mathrm{p}_{1 / 2}$ regions, there is another peak at $714.6 \mathrm{eV}$ assigned to an $\mathrm{Fe}-\mathrm{OH}$ species, from additional oxidation states. Higher oxidation states and satellite features are also observed for single crystal hematite and magnetite, but in our case these are not observed from the low concentration of nanoparticles on the HOPG surface. ${ }^{11,95-97}$ In both types of samples in Fig. 6A, the binding energies remain unchanged with annealing and only an increase in the Fe2p intensities on the sputtered HOPG was observed.

Although there is a minimal signal from the nanoparticles, we only attempt to deconvolute the $\mathrm{Fe} 2 \mathrm{p}$ region, as there are several complications in the proper analysis of the Fe2p region. ${ }^{\text {92,98-101 }}$ The $\mathrm{Fe}^{2+}$ and $\mathrm{Fe}^{3+}$ oxidation states have multiplet splitting in the Fe2p region, which arises from the interaction of $3 d$ electrons of iron and the remaining 2 p electrons after photoelectron ejection, known as Russell-Saunders coupling. ${ }^{92,101}$ Additional satellite peaks, plasmon peaks, surface peaks and initial peaks are present, which makes the interpretation of the Fe2p region complex. Although the $\mathrm{Fe}^{2+} / \mathrm{Fe}^{3+}$ states could not be distinguished with a low signal to noise ratio, XPS analysis confirmed that there was iron on the surface of HOPG after the deposition step and after annealing. Because the signals are very small due to the low density of the iron oxide nanoparticles, the satellite
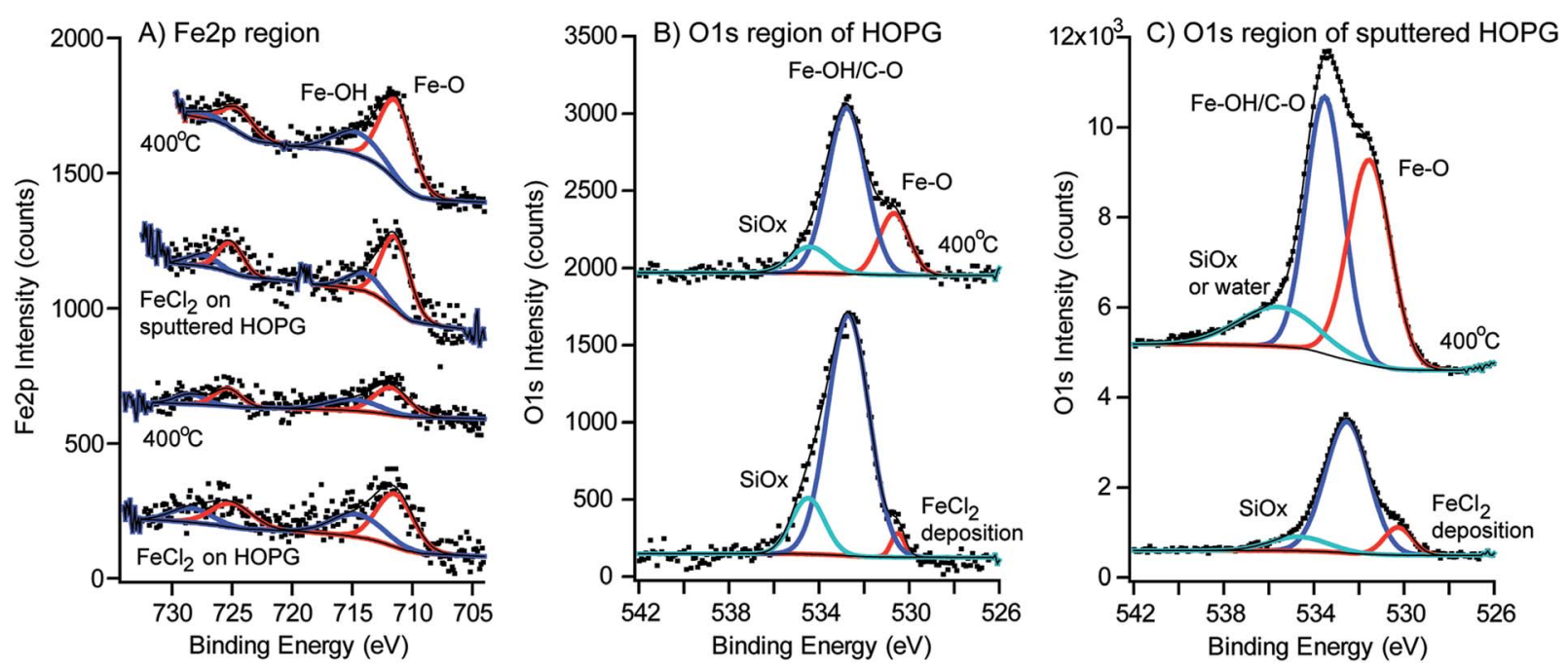

Fig. 6 Fe2p and O1s XPS regions of iron oxide nanoparticles (before and after annealing) on $\mathrm{HOPG}$ and $\mathrm{Ar}^{+}$sputtered $\mathrm{HOPG}$. (A) Fe2p region of iron oxide nanoparticles on HOPG and $\mathrm{Ar}^{+}$sputtered $\mathrm{HOPG}$ before and after annealing at $400{ }^{\circ} \mathrm{C}$. The $\mathrm{O} 1 \mathrm{~s}$ region is shown to compare (B) iron oxide nanoparticles on HOPG after deposition and after annealing at $400{ }^{\circ} \mathrm{C}$ with (C) iron oxide nanoparticles on $\mathrm{Ar}^{+}$sputtered $\mathrm{HOPG}$ after deposition and after annealing at $400{ }^{\circ} \mathrm{C}$. 
peaks of $\mathrm{Fe} 2 \mathrm{p}^{3 / 2}$ and $\mathrm{Fe} 2 \mathrm{p}^{1 / 2}$ are not clearly visible and may be embedded in other peaks. It is expected that several satellite peaks may arise from the presence of $\mathrm{Fe}_{2} \mathrm{O}_{3}$ and $\mathrm{FeOOH}$ species. To unambiguously identify the phases of the iron oxide nanoparticles, crystallographic analysis and high angle annular dark field (HAADF) and STEM imaging were used.

The O1s region in Fig. 6B and $\mathrm{C}$ shows interesting differences in the HOPG and sputtered HOPG samples after deposition of the iron oxide nanoparticles. There is no O1s signal present on unsputtered $\mathrm{HOPG}^{\mathbf{1 0 2}}$ as shown in Fig. S4 in the ESI†, so the oxygen on the surface must originate from the deposited iron oxide nanoparticles. On sputtered HOPG, in Fig. 6C and S4, $\uparrow$ the majority of the $\mathrm{O} 1 \mathrm{~s}$ species at $533.3 \mathrm{eV}$ originate from air oxidation with the sputtered HOPG surface. The O1s binding energies are assigned by comparison to single crystal hematite and magnetite. ${ }^{96,103,104}$ The $\mathrm{O} 1 \mathrm{~s}$ peak at $530.5 \mathrm{eV}$ is assigned to the $\mathrm{Fe}-$ $\mathrm{O}$ species. In single crystal $\alpha-\mathrm{Fe}_{2} \mathrm{O}_{3}(0001)$ and $\mathrm{Fe}_{3} \mathrm{O}_{4}(001)$, the largest peak is located at $530-531 \mathrm{eV}$ from the $\mathrm{Fe}-\mathrm{O}$ binding energy. ${ }^{92,105}$ The peak at the higher binding energy of $532.7 \mathrm{eV}$ is assigned to $\mathrm{C}-\mathrm{O}$ and the $\mathrm{Fe}-\mathrm{OH}$ species on the surface of the iron oxide nanoparticles, attributed to a larger number of hydroxyl groups on the surface of each nanoparticle, from water dissociation prior to analysis. This is expected as iron hydroxides/oxyhydroxides are typically formed as a result of the reaction between $\mathrm{Fe}^{2+}$ and $\mathrm{Fe}^{3+}$ with water and oxygen, from exposure to ambient conditions. ${ }^{106-108}$ The third peak in the O1s region is attributed either to adsorbed water or silicon dioxide contamination on the surface, produced from minor impurities in the precursor.

A separate benchmark experiment was performed where an HOPG surface was sputtered with Ar, exposed to air for 1 hour, and reanalyzed using XPS (Fig. S4 in the ESI $\dagger$ ). Fig. S4† shows that indeed air reacts with the $\mathrm{Ar}^{+}$sputtered HOPG surface, as seen in the O1s region, presumably from the dangling bonds from the defect formation on the surface, producing peaks at $532.4 \mathrm{eV}$ assigned to a $\mathrm{C}-\mathrm{O}$ species and $535.4 \mathrm{eV}$ assigned to residual water. After the sample is exposed to the $\mathrm{FeCl}_{2}(\mathrm{aq})$ solution, there is an increase in the $\mathrm{C}-\mathrm{O}$ peak area and the formation of an $\mathrm{Fe}-\mathrm{O}$ species at $530.3 \mathrm{eV}$. Even on an unsputtered HOPG surface, the $\mathrm{FeCl}_{2}$ reacts with the HOPG surface to form iron oxide nanoparticles at the defect step edges, producing the same two O1s peaks at $530.5 \mathrm{eV}$ and $532.6 \mathrm{eV}$. As shown in Fig. S4† (A), no oxygen is observed on the HOPG surface prior to exposure of the $\mathrm{FeCl}_{2}(\mathrm{aq})$ solution. This suggests that the O1s signal originates from the iron oxide nanoparticles that are grown on the HOPG surface. Further evidence for oxygen only being present on the iron is presented in the STEM images and analysis by EDS below.

After annealing at $400{ }^{\circ} \mathrm{C}$, the ratio of the $\mathrm{Fe}-\mathrm{O}$ and $\mathrm{Fe}-\mathrm{OH} /$ $\mathrm{C}-\mathrm{O}$ peaks in the O1s region changes in peak area, suggesting that iron hydroxide species have been dehydrated from the annealing. The area under the $\mathrm{Fe}-\mathrm{O}$ peaks has increased relative to the $\mathrm{Fe}-\mathrm{OH} / \mathrm{C}-\mathrm{O}$ species. Before annealing, the $\mathrm{Fe}-\mathrm{OH} / \mathrm{C}-$ $\mathrm{O}: \mathrm{Fe}-\mathrm{O}$ ratio in the $\mathrm{O} 1 \mathrm{~s}$ region is observed to be $31.2: 1$ on the plain HOPG surface and 7.1:1 on $\mathrm{Ar}^{+}$sputtered HOPG. After annealing in air, the ratio decreases to $7.1: 1$ on the plain HOPG surface and 3.3:1 on $\mathrm{Ar}^{+}$sputtered HOPG, which suggests a restructuring of the iron oxide nanoparticles. The $\mathrm{C} 1 \mathrm{~s}$ region was compared for the HOPG and $\mathrm{Ar}^{+}$sputtered HOPG, shown in Fig. $\mathrm{S} 5 \dagger$ in the ESI. $\dagger$ A slight increase in the $\mathrm{C}-\mathrm{O}$ concentration was observed after iron oxide nanoparticle nucleation and annealing, but no other significant changes in the $\mathrm{C} 1 \mathrm{~s}$ region were observed. The $\mathrm{Cl} 2 \mathrm{p}$ region was scanned after $\mathrm{FeCl}_{2}$ exposure and no chloride species were detected on the samples (see $\mathrm{Cl} 2 \mathrm{p}$ regions in Fig. S6 in the ESI†).

\section{STEM imaging}

To identify the individual growth and phase of iron oxide nanoparticles on HOPG, the nanoparticles were imaged using scanning transmission electron microscopy (STEM). The HOPG samples were too thick for the STEM analysis, so the iron oxide nanoparticles were grown separately on graphene (6-8 layers of graphene) on lacey carbon 300 mesh copper TEM grids and annealed at $400{ }^{\circ} \mathrm{C}$, as described above for the HOPG samples. The samples were first imaged using FE-SEM imaging to check for reproducibility of similar size iron oxide nanoparticles and that the integrity of the graphene grid remained intact post-annealing.

Fig. 7 shows the HAADF and EDS mapping images of iron oxide nanoparticles after deposition and annealing on the

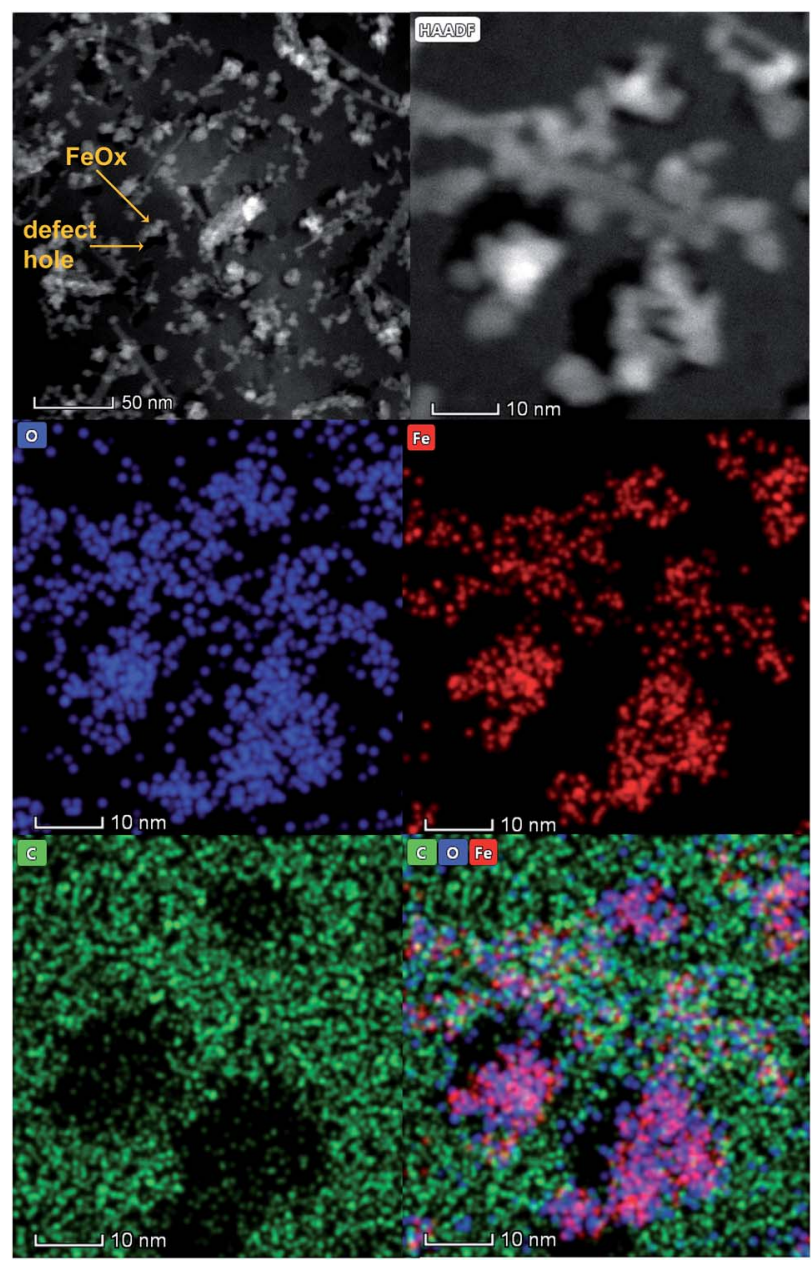

Fig. 7 STEM HAADF images and EDS mapping images of iron oxide particles grown on defects and annealed at $400{ }^{\circ} \mathrm{C}$ on a graphene coated TEM grid. 
graphene coated grid. Arrows point to the defect holes in the graphene and the white areas show the growth of the iron oxide nanoparticles at the defect edges. The grid was characterized using FESEM prior to STEM experiments (Fig. S1 in the ESI $\dagger$ ). The iron oxide nanoparticles analyzed in STEM were only deposited on the 6-8 layer graphene coating and not the copper portion of the grid. The 6-8 layers of graphene allowed for a reasonable model of the HOPG surface in addition to fabricating a specimen thin enough for STEM characterization. Fig. S1† also shows the graphene grid exposed to the $\mathrm{FeCl}_{2}(\mathrm{aq})$ solution for 2 hours and then dried compared to the same grid annealed in air at $400{ }^{\circ} \mathrm{C}$. After iron oxide deposition and rinsing with water, the $\mathrm{FeCl}_{2}$ covers the graphene coating, from the large number of natural defects present on the grid. After annealing, the iron oxide agglomerates to larger and smaller clusters. The smaller clusters on the graphene section were imaged using STEM. The graphene diffraction pattern was observed close to where the nanoparticles were imaged (not shown). The structures of the graphene coated TEM grid and the sputtered HOPG are different, but both contain defects, which allowed for the nucleation and growth of the iron oxide. This difference is demonstrated by the experiment where the iron oxide nanoparticles were grown at the defect step edges on unsputtered HOPG.

The EDS mapping clearly indicates that iron and oxygen signals are from the nanoparticles and the carbon signals from the graphene-coated grid (see Fig. S7 for the EDS spectrum in the ESI $\dagger$ ). It is evident that the surface distribution of oxygen (blue color) is symmetrical to the surface distribution of iron (red color). The green areas show regions of carbon signal originating from the graphene and also regions where iron and oxygen are not present. This clearly indicates that oxygen originates from iron oxide and that the nanoparticles have grown on the defect edges of the graphene grid after annealing at $400{ }^{\circ} \mathrm{C}$.

The HAADF images in Fig. 8 show two types of iron oxide nanoparticles. They were identified as hematite (Fig. 8A and B) and magnetite (Fig. 8C and D) from their corresponding fast Fourier transforms (FFTs) shown at the upper right sides of the images. The images of both hematite (Fig. 8B) and magnetite
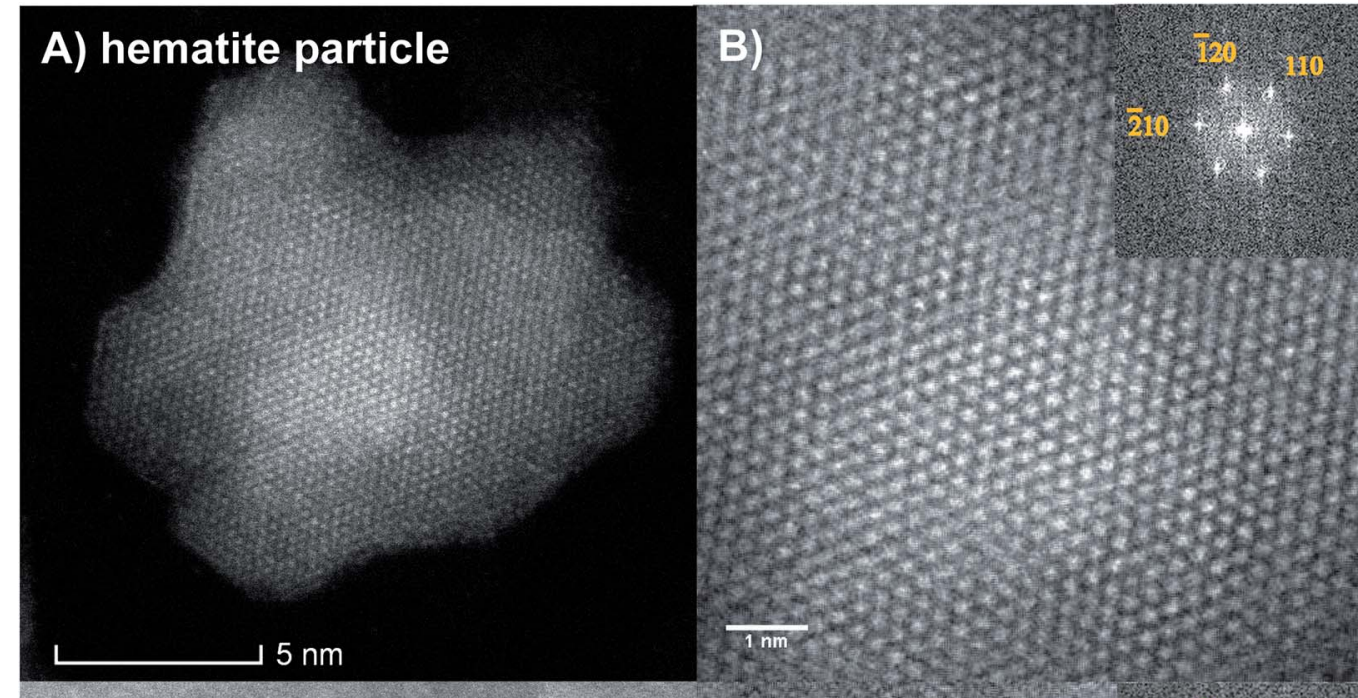

C) magnetite particle
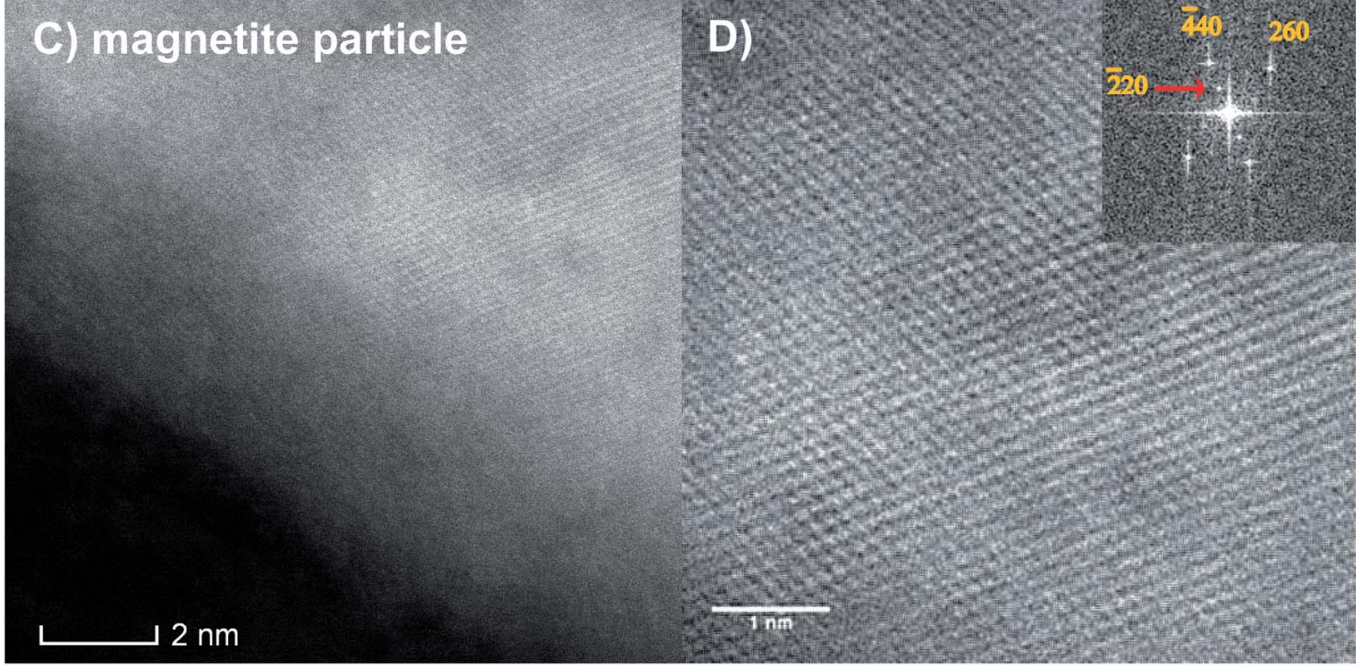

Fig. 8 STEM HAADF images of hematite ( $A$ and $B$ ) and magnetite ( $C$ and $D)$ particles. (A) HAADF image of a hematite particle viewed along the [001] zone axis. (B) A magnified view of the image and its corresponding FFT. (C) HAADF image of a magnetite particle viewed along the [001] zone axis. (D) A magnified view of the image and its corresponding FFT. The majority of the particles were identified as hematite. 
(Fig. 8D) clearly show the Fe atom columns, which is a good indication of the crystallinity of iron oxide nanoparticles. The FFTs show the co-existence of hexagonal $\alpha-\mathrm{Fe}_{2} \mathrm{O}_{3}$ (hematite) and FCC spinel $\mathrm{Fe}_{3} \mathrm{O}_{4}$ (magnetite) phases. The FFT of Fig. 8B corresponds to a particle with a hexagonal hematite phase projected along the [001] zone axis. All points represent $\{11 \overline{2} 0\}$ planes $(d=2.5 \AA)$. The FFT of Fig. 8D corresponds to a particle belonging to the cubic magnetite phase projected along the [001] zone axis. This is evident from the presence of $\{220\}(d=$ $2.9 \AA)$ and $\{620\}(d=1.3 \AA)$ planes. Although both magnetite and hematite crystal phases were identified on the surface of HOPG, the majority of the nanoparticles were observed to have the stoichiometry of hematite, according to the EDS spectrum of the STEM images (Fig. S3†). This elemental ratio is expected when annealing iron oxide particles in excess oxygen (e.g. air), according to the phase diagram of iron oxide.

\section{Discussion}

According to our analysis, we observed the spontaneous and selective deposition of iron oxide (primarily $\alpha-\mathrm{Fe}_{2} \mathrm{O}_{3}$ ) at natural step edges and sputtered defect areas of HOPG. A mechanism for the deposition and conversion of $\mathrm{FeCl}_{2}(\mathrm{aq})$ into iron oxide nanoparticles is proposed below (Scheme 1). First, the $\mathrm{Fe}^{2+}(\mathrm{aq})$ must be reduced upon spontaneous deposition onto the $\mathrm{sp}^{3}$ defect sites to create nucleation seeds before further growth to nanoparticles. Previous studies found the correlation reduction potential of the $\mathrm{Au}\left(\mathrm{HAuCl}_{4}\right), \mathrm{Pt}\left(\mathrm{Na}_{2} \mathrm{PtCl}_{4}\right)$, and $\mathrm{Fe}\left(\mathrm{NO}_{3}\right)_{3}$ precursors and whether deposition was spontaneous on carbon nanotubes. ${ }^{\mathbf{9}, 65}$ The reduction potentials of $\mathrm{AuCl}_{4}{ }^{-}$and $\mathrm{PtCl}_{4}{ }^{2-}$ on single walled carbon nanotubes (SWCNTs) are $+1.002 \mathrm{~V}$ and $+0.775 \mathrm{~V}$, respectively, with respect to the standard hydrogen electrode (SHE). For the study with $\mathrm{Fe}\left(\mathrm{NO}_{3}\right)_{3}$, defects in the form of organic functionalities were found to facilitate the electron transfer reaction between $\mathrm{Fe}^{3+}$ and the MWCNT substrate, reducing $\mathrm{Fe}^{3+}$ into $\mathrm{Fe}^{2+}$. There, electron rich carbon nanotubes donate electrons to $\mathrm{Pt}^{2+}, \mathrm{Au}^{3+}$, and $\mathrm{Fe}^{3+}$ cations, reducing them upon selective deposition of $\mathrm{Au}, \mathrm{Pt}$ and $\mathrm{Fe}_{3} \mathrm{O}_{4}$ at the SWCNT defects., ${ }^{\mathbf{9} 33,64}$ For our study, the standard reduction potential of $\mathrm{Fe}^{3+}$ to $\mathrm{Fe}^{2+}$ is $+0.771 \mathrm{~V}$, a similar value to that observed for $\mathrm{Au}$ $\left(\mathrm{HAuCl}_{4}\right)$ and $\mathrm{Pt}\left(\mathrm{Na}_{2} \mathrm{PtCl}_{4}\right){ }^{65}$ Therefore, in the presence of a graphite surface in aqueous solution, $\mathrm{Fe}^{2+}$ is susceptible to oxidation into $\mathrm{Fe}^{3+}$ by water hydrolysis. The proposed mechanism below suggests that the $\mathrm{Fe}^{2+}$ is oxidized to $\mathrm{Fe}^{3+}$ and forms hydroxide and oxyhydroxide species. The reduction potential of $\mathrm{Fe}^{2+}$ to $\mathrm{Fe}-\mathrm{OH}$ is favorable, at $-0.44 \mathrm{~V}$, and the reduction potential to reduce $\mathrm{Fe}(\mathrm{OH})_{2}$ to $\mathrm{Fe}^{0}$ is $-0.89 \mathrm{~V} .{ }^{109} \mathrm{It}$ is possible that the spontaneous reaction could occur from the $\mathrm{Fe}^{2+}$ with dissolved oxygen and water to form iron oxides and hydroxides, such as $\mathrm{Fe}(\mathrm{OH})_{2}$. Such iron species are easily oxidized by dissolved oxygen into higher hydroxides, $\mathrm{Fe}(\mathrm{OH})_{3}$ and oxyhydroxides (FeOOH). These products in the reaction steps below are evident from the XPS data, where $\mathrm{Fe}-\mathrm{OH} / \mathrm{OOH}$ is the primary peak in the XPS O1s region.

After annealing at $400{ }^{\circ} \mathrm{C}$, the iron oxide nanoparticles in the defect areas, consisting of $\mathrm{sp}^{3}$ carbon, are found to diffuse and coalesce to larger core-shell-like particles. The observed AFM and FESEM images suggest that the nanoparticles in the terrace region ( $\mathrm{sp}^{2}$ carbon) of the HOPG surface do not move or significantly change in size after annealing. These changes are attributed to the differences in the sites available on the HOPG surface. The $\mathrm{sp}^{3}$ carbon sites on the defect areas, including the step edges of HOPG, are highly reactive, thus allowing for facile adsorption of the iron oxide nanoparticles. After annealing, the nanoparticles in the defect areas diffuse and coalesce, while the nanoparticles on the defects in the terrace region of the HOPG surface do not. This suggests that the iron oxide nanoparticles are not tightly bound to the surface defects as observed for the particles on the terrace.

The XPS results showed that nanoparticles are primarily $\mathrm{Fe}-$ $\mathrm{OH}$ species before annealing, with a +3 oxidation state. After annealing at $400{ }^{\circ} \mathrm{C}$ and oxidation in air, the $\mathrm{Fe}-\mathrm{OH}$ species undergoes dehydration and restructures into $\alpha-\mathrm{Fe}_{2} \mathrm{O}_{3}$, as observed by the change in surface species observed in the O1s XPS spectra and the HAADF images. The diffraction pattern showed that both $\alpha-\mathrm{Fe}_{2} \mathrm{O}_{3}$ and $\mathrm{Fe}_{3} \mathrm{O}_{4}$ are present in defects with the majority being $\alpha-\mathrm{Fe}_{2} \mathrm{O}_{3}$. However, after annealing, conversion of iron oxyhydroxides and hydroxides is incomplete after 2 hours of air oxidation. Further annealing may completely convert the particles to $\mathrm{Fe}_{2} \mathrm{O}_{3}$. Some of the remaining $\mathrm{Fe}-\mathrm{OH} /$ $\mathrm{OOH}$ signal in the O1s XPS region can be explained through the adsorption of water from exposure to ambient conditions, which leads to the regeneration of iron hydroxides and oxyhydroxides. This agrees with reported literature studies which show that even pure single crystal hematite also has a thin layer of iron oxyhydroxides as a result of the influence of atmospheric moisture. ${ }^{\mathbf{9 4 9}}$ EDS mapping confirmed that the aggregated iron oxide nanoparticles grow in the defects as iron oxide, with no further oxidation of the graphitic surface.

According to the above proposed mechanism, it is possible to form both hematite and magnetite on the HOPG surface. Annealing in air at high temperature facilitates the conversion of most of the magnetite $\left(\mathrm{Fe}_{3} \mathrm{O}_{4}\right)$ into hematite $\left(\mathrm{Fe}_{2} \mathrm{O}_{3}\right)$ with higher oxidation states. ${ }^{\mathbf{1 1 0}}$ Apart from oxidation, annealing facilitates the removal of water (dehydration), which converts

$$
\begin{gathered}
\mathrm{FeCl}_{2} \rightarrow \mathrm{Fe}^{2+}+2 \mathrm{Cl}^{-} \\
\mathrm{Fe}^{2+}+2 \mathrm{H}_{2} \mathrm{O} \rightarrow \mathrm{Fe}(\mathrm{OH})_{2}+2 \mathrm{H}^{+} \\
6 \mathrm{Fe}(\mathrm{OH})_{2}+\mathrm{O}_{2} \underset{\Delta 400 \mathrm{C}}{\longrightarrow} 2 \mathrm{Fe}_{3} \mathrm{O}_{4}+6 \mathrm{H}_{2} \mathrm{O} \\
4 \mathrm{Fe}(\mathrm{OH})_{2}+\mathrm{O}_{2} \underset{\Delta 400 \mathrm{C}}{\longrightarrow} 2 \mathrm{Fe}_{2} \mathrm{O}_{3}+4 \mathrm{H}_{2} \mathrm{O} \\
4 \mathrm{Fe}_{3} \mathrm{O}_{4}+\mathrm{O}_{2} \underset{\Delta}{\rightarrow} 6 \mathrm{Fe}_{2} \mathrm{O}_{3} \\
\mathrm{Fe}_{2} \mathrm{O}_{3}+\mathrm{H}_{2} \mathrm{O} \rightarrow 2 \mathrm{FeOOH}
\end{gathered}
$$

Scheme 1 Proposed reaction mechanism of iron oxide nanoparticle deposition, nucleation and transformation on HOPG defects and formation of iron oxides and hydroxides. Further annealing in air produces primarily $\mathrm{Fe}_{2} \mathrm{O}_{3}$, through dehydration of hydroxides and oxyhydroxides. 
iron hydroxides and oxyhydroxides into iron oxide. However, when the HOPG surface is exposed to air, a certain amount of atmospheric water vapor is condensed on the HOPG surface which could react with hematite and regenerate a certain amount of iron oxyhydroxides (Fe-OOH), thus resulting in the largest $\mathrm{Fe}-\mathrm{OH}$ species in the O1s XPS region. This agrees with studies on single crystal hematite, where a thin layer of iron oxyhydroxides is produced as a result of the influence of ambient moisture..$^{94,96,106-108}$

Overall, this study confirmed the feasibility of spontaneous and selective deposition of iron oxide (hematite) nanoparticles on predefined areas (defect sites) on HOPG using a simple metal precursor. These results show an easy method for selective metal deposition for hematite nanoparticles as model heterogeneous catalysts that are stable at modest temperatures.

\section{Conclusions}

Iron oxide nanoparticles were selectively deposited on HOPG defects using an $\mathrm{FeCl}_{2}(\mathrm{aq})$ precursor. Nanoparticles were found to adsorb to defects in both the terrace areas and defect areas on the HOPG surface at room temperature. The binding energy between the terrace and iron oxide nanoparticles is relatively strong compared to the bonds formed in between iron oxide nanoparticles and defect sites of HOPG, thus allowing the nanoparticles in the defect areas ( $\mathrm{sp}^{3}$ carbon) to diffuse and coalesce. The iron oxide nanoparticles in the defect areas serve as the primary nucleation sites for iron oxide nanoparticles. Additional studies are required to find the exact nature of their adsorption. When the temperature increases above $400{ }^{\circ} \mathrm{C}$, the HOPG surface is oxidized, forming hematite nanoparticles. The iron facilitates the diffusion and etching of the HOPG surface above $400{ }^{\circ} \mathrm{C}$. These studies have shown that spontaneous deposition of iron oxide nanoparticles occurs at the HOPG defects. Upon annealing at $400{ }^{\circ} \mathrm{C}$, the iron oxide nanoparticles coalesce to form primarily hematite. These fundamental studies suggest a simple method for spontaneous and selective deposition on graphite as a model system for potential heterogeneous catalysts.

\section{Conflicts of interest}

There are no conflicts to declare.

\section{Author contributions}

CA prepared the samples, analyzed the data and wrote the manuscript. TRL performed the XPS, assisted with XPS data analysis and editing of the manuscript. PM imaged the samples with STEM and assisted with STEM data analysis. AD collected and analyzed the AFM images. KAP conceived the idea, imaged samples using the FESEM, and guided the data analysis and manuscript.

\section{Acknowledgements}

Equipment for obtaining the AFM images in this project was provided by NSF CHE \#1725818. The electron microscopy research was performed at the Applied Chemical and Morphological Analysis Laboratory, at Michigan Technological University. The electron microscopy facility is supported by NSF MRI 1429232. We acknowledge the Michigan Tech REF-RS fund for support of this work and the David J. and Valeria Pruett Graduate Research Fellowship. We acknowledge the Applied Chemical and Morphological Analysis Laboratory (ACMAL) for staff assistance and use of facilities.

\section{References}

1 D. M. Cwiertny, M. A. Young and V. H. Grassian, Chemistry and photochemistry of mineral dust aerosol, Annu. Rev. Phys. Chem., 2008, 59, 27-51.

2 P. A. Kozin, A. Shchukarev and J. F. Boily, Electrolyte Ion Binding at Iron Oxyhydroxide Mineral Surfaces, Langmuir, 2013, 29(39), 12129-12137.

3 G. Rubasinghege, S. Elzey, J. Baltrusaitis, P. M. Jayaweera and V. H. Grassian, Reactions on Atmospheric Dust Particles: Surface Photochemistry and Size-Dependent Nanoscale Redox Chemistry, J. Phys. Chem. Lett., 2010, 1(11), 1729-1737.

$4 \mathrm{H}$. A. Al-Abadleh and V. H. Grassian, Oxide surfaces as environmental interfaces, Surf. Sci. Rep., 2003, 52(3-4), 63-161.

5 C. R. Usher, A. E. Michel and V. H. Grassian, Reactions on mineral dust, Chem. Rev., 2003, 103(12), 4483-4939.

6 M. F. Hochella, Mineral surfaces - their characterization and their chemical, physical and reactive nature, ed. D. J.Vaughan and R. A. D.Pattrick, 1995, pp. 17-60.

7 S. Selvaraj, H. Moon, J.-Y. Yun and D.-H. Kim, Iron oxide grown by low-temperature atomic layer deposition, Korean J. Chem. Eng., 2016, 33(12), 3516-3522.

8 Z. Sun, X. Cai, Y. Song and X.-X. Liu, Electrochemical deposition of honeycomb magnetite on partially exfoliated graphite as anode for capacitive applications, J. Power Sources, 2017, 359, 57-63.

9 S. Song, R. Rao, H. Yang, H. Liu and A. Zhang, Facile synthesis of $\mathrm{Fe}_{3} \mathrm{O}_{4} /$ MWCNTs by spontaneous redox and their catalytic performance, Nanotechnology, 2010, 21(18), 185602.

10 L. S. Arias, J. P. Pessan, A. P. M. Vieira, T. M. T. Lima, A. C. B. Delbem and D. R. Monteiro, Iron Oxide Nanoparticles for Biomedical Applications: A Perspective on Synthesis, Drugs, Antimicrobial Activity, and Toxicity, Antibiotics, 2018, 7(2), 46.

11 G. S. Parkinson, Iron oxide surfaces, Surf. Sci. Rep., 2016, 71(1), 272-365.

$12 \mathrm{~W}$. Weiss and W. Ranke, Surface chemistry and catalysis on well-defined epitaxial iron-oxide layers, Prog. Surf. Sci., 2002, 70(1-3), 1-151.

13 F. Genuzio, A. Sala, T. Schmidt, D. Menzel and H. J. Freund, Phase transformations in thin iron oxide films: spectromicroscopic study of velocity and shape of the reaction fronts, Surf. Sci., 2016, 648, 177-187.

14 H. Pan, X. Meng and G. Qin, Hydrogen generation by water splitting on hematite (0001) surfaces: first-principles 
calculations, Phys. Chem. Chem. Phys., 2014, 16(46), 2544225448.

15 M. Rioult, D. Stanescu, E. Fonda, A. Barbier and H. Magnan, Oxygen Vacancies Engineering of Iron Oxides Films for Solar Water Splitting, J. Phys. Chem. C, 2016, 120(14), 7482-7490.

16 Y. Ling, G. Wang, D. A. Wheeler, J. Z. Zhang and Y. Li, SnDoped Hematite Nanostructures for Photoelectrochemical Water Splitting, Nano Lett., 2011, 11(5), 2119-2125.

17 C. M. Eggleston, A. G. Stack, K. M. Rosso, S. R. Higgins, A. M. Bice, S. W. Boese, et al., The structure of hematite (alpha-Fe(2)O(3)) (001) surfaces in aqueous media: scanning tunneling microscopy and resonant tunneling calculations of coexisting $\mathrm{O}$ and $\mathrm{Fe}$ terminations, Geochim. Cosmochim. Acta, 2003, 67(5), 985-1000.

18 T. Kandemir, M. E. Schuster, A. Senyshyn, M. Behrens and R. Schlogl, The Haber-Bosch Process Revisited: On the Real Structure and Stability of “Ammonia Iron" under Working Conditions, Angew. Chem., Int. Ed., 2013, 52(48), 1272312726.

19 L. A. Cano, A. A. G. Blanco, G. Lener, S. G. Marchetti and K. Sapag, Effect of the support and promoters in FischerTropsch synthesis using supported Fe catalysts, Catal. Today, 2017, 282, 204-213.

20 Y. Cheng, J. Lin, K. Xu, H. Wang, X. Yao, Y. Pei, et al., Fischer-Tropsch Synthesis to Lower Olefins over Potassium-Promoted Reduced Graphene Oxide Supported Iron Catalysts, ACS Catal., 2016, 6(1), 389-399.

21 X. Z. Duan, D. Wang, G. Qian, J. C. Walmsley, A. Holmen, D. Chen, et al., Fabrication of K-promoted iron/carbon nanotubes composite catalysts for the Fischer-Tropsch synthesis of lower olefins, J. Energy Chem., 2016, 25(2), 311-317.

22 D. Wang, B. X. Chen, X. Z. Duan, D. Chen and X. G. Zhou, Iron-based Fischer-Tropsch synthesis of lower olefins: The nature of chi- $\mathrm{Fe}_{5} \mathrm{C}_{2}$ catalyst and why and how to introduce promoters, J. Energy Chem., 2016, 25(6), 911-916.

23 D. H. Chun, J. C. Park, S. Y. Hong, J. T. Lim, C. S. Kim, H. T. Lee, et al., Highly selective iron-based FischerTropsch catalysts activated by $\mathrm{CO}_{2}$-containing syngas, $J$. Catal., 2014, 317, 135-143.

24 A. J. M. Mackus, M. J. M. Merkx and W. M. M. Kessels, From the Bottom-Up: Toward Area-Selective Atomic Layer Deposition with High Selectivity, Chem. Mater., 2019, 31(1), 2-12.

25 J. A. Singh, N. F. W. Thissen, W. H. Kim, H. Johnson, W. M. M. Kessels, A. A. Bol, et al., Area-Selective Atomic Layer Deposition of Metal Oxides on Noble Metals through Catalytic Oxygen Activation, Chem. Mater., 2018, 30(3), 663-670.

26 A. Mameli, M. J. M. Merkx, B. Karasulu, F. Roozeboom, W. M. M. Kessels and A. J. M. Mackus, Area-Selective Atomic Layer Deposition of $\mathrm{SiO}_{2}$ Using Acetylacetone as a Chemoselective Inhibitor in an ABC-Type Cycle, ACS Nano, 2017, 11(9), 9303-9311.
27 A. J. M. Mackus, A. A. Bol and W. M. M. Kessels, The use of atomic layer deposition in advanced nanopatterning, Nanoscale, 2014, 6(19), 10941-10960.

28 B. Bowden, M. Davies, P. R. Davies, S. Guan, D. J. Morgan, V. Roberts, et al., The deposition of metal nanoparticles on carbon surfaces: the role of specific functional groups, Faraday Discuss., 2018, 208, 455-470.

29 J. L. Lu, J. W. Elam and P. C. Stair, Atomic layer depositionSequential self-limiting surface reactions for advanced catalyst "bottom-up" synthesis, Surf. Sci. Rep., 2016, 71(2), 410-472.

30 J. X. Xie, H. M. T. Galvis, A. C. J. Koeken, A. Kirilin, A. I. Dugulan, M. Ruitenbeek, et al., Size and Promoter Effects on Stability of Carbon-Nanofiber-Supported IronBased Fischer-Tropsch Catalysts, ACS Catal., 2016, 6(6), 4017-4024.

31 S. Das and W. Daud, A review on advances in photocatalysts towards CO2 conversion, RSC Adv., 2014, 4(40), 2085620893.

32 J. L. Qiao, Y. Y. Liu, F. Hong and J. J. Zhang, A review of catalysts for the electroreduction of carbon dioxide to produce low-carbon fuels, Chem. Soc. Rev., 2014, 43(2), 631-675.

33 S. Chaturvedi, P. N. Dave and N. K. Shah, Applications of nano-catalyst in new era, J. Saudi Chem. Soc., 2012, 16(3), 307-325.

34 E. Sanchez, Y. Yang, J. Find, T. Braun, R. Schoonmaker, T. Belz, H. Sauer, O. Spillecke, Y. Uchida and R. Schlögl, Elemental carbon as catalytic material: Recent trends and perspectives, Stud. Surf. Sci. Catal., 1999, 121, 317-326.

35 K. S. Novoselov, A. K. Geim, S. V. Morozov, D. Jiang, Y. Zhang, S. V. Dubonos, et al., Electric field effect in atomically thin carbon films, Science, 2004, 306(5696), 666-669.

36 E. P. Randviir, D. A. C. Brownson and C. E. Banks, A decade of graphene research: production, applications and outlook, Mater. Today, 2014, 17(9), 426-432.

37 A. Felten, B. S. Flavel, L. Britnell, A. Eckmann, P. Louette, J.-J. Pireaux, et al., Single- and Double-Sided Chemical Functionalization of Bilayer Graphene, Small, 2013, 9(4), 631-639.

38 M. Acik and Y. J. Chabal, Nature of Graphene Edges: A Review, Jpn. J. Appl. Phys., 2011, 50(7), 070101.

39 D. R. Dreyer, S. Park, C. W. Bielawski and R. S. Ruoff, The chemistry of graphene oxide, Chem. Soc. Rev., 2010, 39(1), 228-240.

40 A. Stein, Z. Wang and M. A. Fierke, Functionalization of Porous Carbon Materials with Designed Pore Architecture, Adv. Mater., 2009, 21(3), 265-293.

41 T. Szabo, O. Berkesi, P. Forgo, K. Josepovits, Y. Sanakis, D. Petridis, et al., Evolution of surface functional groups in a series of progressively oxidized graphite oxides, Chem. Mater., 2006, 18(11), 2740-2749.

$42 \mathrm{P}$. V. Kamat, Meeting the clean energy demand: Nanostructure architectures for solar energy conversion, $J$. Phys. Chem. C, 2007, 111(7), 2834-2860. 
43 D. Zhu, J. A. Bandy, S. Li and R. J. Hamers, Aminoterminated diamond surfaces: photoelectron emission and photocatalytic properties, Surf. Sci., 2016, 650, 295-301.

44 H. B. Profijt, S. E. Potts, M. C. M. van de Sanden and W. M. M. Kessels, Plasma-Assisted Atomic Layer Deposition: Basics, Opportunities, and Challenges, J. Vac. Sci. Technol., A, 2011, 29(5), 050801.

45 X. Glad, L. de Poucques, J. A. Jaszczak, M. Belmahi, J. Ghanbaja and J. Bougdira, Plasma synthesis of hexagonal-pyramidal graphite hillocks, Carbon, 2014, 76, 330-340.

46 E. C. Walter, M. P. Zach, F. Favier, B. J. Murray, K. Inazu, J. C. Hemminger, et al., Metal nanowire arrays by electrodeposition, ChemPhysChem, 2003, 4(2), 131-138.

47 C. E. Cross, J. C. Hemminger and R. M. Penner, Physical vapor deposition of one-dimensional nanoparticle arrays on graphite: seeding the electrodeposition of gold nanowires, Langmuir, 2007, 23(20), 10372-10379.

48 H. B. R. Lee and S. F. Bent, Formation of Continuous Pt Films on the Graphite Surface by Atomic Layer Deposition with Reactive O-3, Chem. Mater., 2015, 27(19), 6802-6809.

49 Y. J. Zhu, A. Schnieders, J. D. Alexander and T. P. Beebe, Pittemplated synthesis and oxygen adsorption properties of gold nanostructures on highly oriented pyrolytic graphite, Langmuir, 2002, 18(15), 5728-5733.

$50 \mathrm{~J}$. Taing, M. H. Cheng and J. C. Hemminger, Photodeposition of $\mathrm{Ag}$ or $\mathrm{Pt}$ onto $\mathrm{TiO} 2$ Nanoparticles Decorated on Step Edges of HOPG, ACS Nano, 2011, 5(8), 6325-6333.

51 W. Yan, T. Ayvazian, J. Kim, Y. Liu, K. C. Donavan, W. Xing, et al., Mesoporous Manganese Oxide Nanowires for HighCapacity, High-Rate, Hybrid Electrical Energy Storage, ACS Nano, 2011, 5(10), 8275-8287.

52 Q. Li, M. A. Brown, J. C. Hemminger and R. M. Penner, Luminescent polycrystalline cadmium selenide nanowires synthesized by cyclic electrodeposition/stripping coupled with step edge decoration, Chem. Mater., 2006, 18(15), 3432-3441.

53 B. J. Murray, Q. Li, J. T. Newberg, J. C. Hemminger and R. M. Penner, Silver oxide microwires: electrodeposition and observation of reversible resistance modulation upon exposure to ammonia vapor, Chem. Mater., 2005, 17(26), 6611-6618.

54 M. N. Ding, Y. F. Tang and A. Star, Understanding Interfaces in Metal-Graphitic Hybrid Nanostructures, $J$. Phys. Chem. Lett., 2013, 4(1), 147-160.

55 R. P. Galhenage, K. Xie, W. J. Diao, J. M. M. Tengco, G. S. Seuser, J. R. Monnier, et al., Platinum-ruthenium bimetallic clusters on graphite: a comparison of vapor deposition and electroless deposition methods, Phys. Chem. Chem. Phys., 2015, 17(42), 28354-28363.

56 M. F. Juarez, S. Fuentes, G. J. Soldano, L. Avalle and E. Santos, Spontaneous formation of metallic nanostructures on highly oriented pyrolytic graphite (HOPG): an ab initio and experimental study, Faraday Discuss., 2014, 172, 327-347.
57 Y. J. Zhu, J. D. McBride, T. A. Hansen and T. P. Beebe, Controlled production of molecule corrals using cesium ion bombardment: a TOF-SIMS, XPS, and STM study, J. Phys. Chem. B, 2001, 105(10), 2010-2018.

58 I. N. Kholmanov, J. Edgeworth, E. Cavaliere, L. Gavioli, C. Magnuson and R. S. Ruoff, Healing of Structural Defects in the Topmost Layer of Graphite by Chemical Vapor Deposition, Adv. Mater., 2011, 23(14), 1675-1678.

59 A. Clemens, L. Hellberg, H. Gronbeck and D. Chakarov, Water desorption from nanostructured graphite surfaces, Phys. Chem. Chem. Phys., 2013, 15(47), 20456-20462.

60 D. R. Kauffman and A. Star, Graphene versus carbon nanotubes for chemical sensor and fuel cell applications, Analyst, 2010, 135(11), 2790-2797.

61 D. R. Kauffman and A. Star, Chemically induced potential barriers at the carbon nanotube-metal nanoparticle interface, Nano Lett., 2007, 7(7), 1863-1868.

62 W. Luo, W. van der Veer, P. Chu, D. L. Mills, R. M. Penner and J. C. Hemminger, Polarization-dependent surface enhanced Raman scattering from silver 1D nanoparticle arrays, J. Phys. Chem. C, 2008, 112(31), 11609-11613.

63 H. C. Choi, M. Shim, S. Bangsaruntip and H. J. Dai, Spontaneous reduction of metal ions on the sidewalls of carbon nanotubes, J. Am. Chem. Soc., 2002, 124(31), 90589059.

64 B. M. Quinn, C. Dekker and S. G. Lemay, Electrodeposition of noble metal nanoparticles on carbon nanotubes, J. Am. Chem. Soc., 2005, 127(17), 6146-6147.

65 X. R. Zhang, W. Ooki, Y. R. Kosaka, A. Okonogi, G. Marzun, P. Wagener, et al., Effect of $\mathrm{pH}$ on the spontaneous synthesis of palladium nanoparticles on reduced graphene oxide, Appl. Surf. Sci., 2016, 389, 911-915.

66 F. Stevens, L. A. Kolodny and T. P. Beebe, Kinetics of graphite oxidation: Monolayer and multilayer etch pits in HOPG studied by STM, J. Phys. Chem. B, 1998, 102(52), 10799-10804.

67 S. Tougaard, Accuracy of the non-destructive surface nanostructure quantification technique based on analysis of the XPS or AES peak shape, Surf. Interface Anal., 1998, 26(4), 249-269.

68 S. Doniach and M. Sunjic, Many-electron singularity in Xray photoemission and X-ray line spectra from metals, $J$. Phys. C: Solid State Phys., 1970, 3(2), 285-291.

$69 \mathrm{H}$. Estrade-Szwarckopf, XPS photoemission in carbonaceous materials: A "defect" peak beside the graphitic asymmetric peak, Carbon, 2004, 42(8-9), 17131721.

70 J. A. Leiro, M. H. Heinonen, T. Laiho and I. G. Batirev, Corelevel XPS spectra of fullerene, highly oriented pyrolitic graphite, and glassy carbon, J. Electron Spectrosc. Relat. Phenom., 2003, 128(2-3), 205-213.

71 P. Stadelmann, Electron Microscopy Software, version 4, CIME-EPFL, Lausanne, Switzerland, 2014.

72 S. V. Morozov, K. S. Novoselov, M. I. Katsnelson, F. Schedin, D. C. Elias, J. A. Jaszczak, et al., Giant intrinsic carrier mobilities in graphene and its bilayer, Phys. Rev. Lett., 2008, 100(1), 016602. 
73 M. S. Dresselhaus, Fifty years in studying carbon-based materials, Phys. Scr., 2012, 014002.

74 Y. J. Zhu, T. A. Hansen, S. Ammermann, J. D. McBride and T. P. Beebe, Nanometer-size monolayer and multilayer molecule corrals on HOPG: a depth-resolved mechanistic study by STM, J. Phys. Chem. B, 2001, 105(32), 7632-7638.

75 C. Bosch-Navarro, J. P. Rourke and N. R. Wilson, Controlled electrochemical and electroless deposition of noble metal nanoparticles on graphene, RSC Adv., 2016, 6(77), 7379073796.

76 A. V. Nartova, A. V. Bukhtiyarov, R. I. Kvon, E. M. Makarov, I. P. Prosvirin and V. I. Bukhtiyarov, Atomic scale structural defects in the graphite layer for model catalysis, Surf. Sci., 2018, 677, 90-92.

77 M. Favaro, L. Perini, S. Agnoli, C. Durante, G. Granozzi and A. Gennaro, Electrochemical behavior of $\mathrm{N}$ and $\mathrm{Ar}$ implanted highly oriented pyrolytic graphite substrates and activity toward oxygen reduction reaction, Electrochim. Acta, 2013, 88, 477-487.

78 D. V. Demidov, I. P. Prosvirin, A. M. Sorokin and V. I. Bukhtiyarov, Model Ag/HOPG catalysts: preparation and STM/XPS study, Catal. Sci. Technol., 2011, 1(8), 14321439.

79 C. Morant, L. Soriano, J. F. Trigo and J. M. Sanz, Atomic force microscope study of the early stages of $\mathrm{NiO}$ deposition on graphite and mica, Thin Solid Films, 1998, 317(1-2), 59-63.

80 M. Lukas, V. Meded, A. Vijayaraghavan, L. Song, P. M. Ajayan, K. Fink, et al., Catalytic subsurface etching of nanoscale channels in graphite, Nat. Commun., 2013, 4, 1379.

81 A. V. Bukhtiyarov, I. P. Prosvirin and V. I. Bukhtiyarov, XPS/ STM study of model bimetallic Pd-Au/HOPG catalysts, Appl. Surf. Sci., 2016, 367, 214-221.

82 Y. H. Zhou, A. Lii-Rosales, M. Kim, M. Wallingford, D. P. Jing, M. C. Tringides, et al., Defect-mediated, thermally-activated encapsulation of metals at the surface of graphite, Carbon, 2018, 127, 305-311.

83 Y. Han, A. Lii-Rosales, Y. Zhou, C. J. Wang, M. Kim, M. C. Tringides, et al., Nucleation and growth kinetics for intercalated islands during deposition on layered materials with isolated pointlike surface defects, Phys. Rev. Mater., 2017, 1(5), 053403.

84 A. Lii-Rosales, Y. Han, J. W. Evans, D. P. Jing, Y. H. Zhou, M. C. Tringides, et al., Formation of Multilayer Cu Islands Embedded Beneath the Surface of Graphite: Characterization and Fundamental Insights, J. Phys. Chem. C, 2018, 122(8), 4454-4469.

85 A. Lii-Rosales, Y. Han, K. M. Yu, D. P. Jing, N. Anderson, D. Vaknin, et al., Reverse-engineering of graphene on metal surfaces: a case study of embedded ruthenium, Nanotechnology, 2018, 29(50), 505601.

86 A. Lii-Rosales, Y. H. Zhou, M. Wallingford, C. Z. Wang, M. C. Tringides and P. A. Thiel, Formation of dysprosium carbide on the graphite (0001) surface, Phys. Rev. Mater., 2017, 1(2), 026002.
87 E. J. Kwolek, H. P. Lei, A. Lii-Rosales, M. Wallingford, Y. H. Zhou, C. Z. Wang, et al., Adsorption of dysprosium on the graphite (0001) surface: Nucleation and growth at 300 K., J. Chem. Phys., 2016, 145(21), 211902.

88 D. Appy, H. P. Lei, Y. Han, C. Z. Wang, M. C. Tringides, D. H. Shao, et al., Determining whether metals nucleate homogeneously on graphite: a case study with copper, Phys. Rev. B: Condens. Matter Mater. Phys., 2014, 90(19), 195406.

89 D. Appy, H. P. Lei, C. Z. Wang, M. C. Tringides, D. J. Liu, J. W. Evans, et al., Transition metals on the (0001) surface of graphite: fundamental aspects of adsorption, diffusion, and morphology, Prog. Surf. Sci., 2014, 89(3-4), 219-238.

90 Y. F. Tang, G. P. Kotchey, H. Vedala and A. Star, Electrochemical Detection with Platinum Decorated Carbon Nanomaterials, Electroanalysis, 2011, 23(4), 870877.

91 P. V. Kamat, Graphene-based nanoarchitectures. Anchoring semiconductor and metal nanoparticles on a twodimensional carbon support, J. Phys. Chem. Lett., 2009, 1(2), 520-527.

92 S. Poulin, R. Franca, L. Moreau-Belanger and E. Sacher, Confirmation of X-ray Photoelectron Spectroscopy Peak Attributions of Nanoparticulate Iron Oxides, Using Symmetric Peak Component Line Shapes, J. Phys. Chem. C, 2010, 114(24), 10711-10718.

93 D. Q. Yang and E. Sacher, Characterization and Oxidation of Fe Nanoparticles Deposited onto Highly Oriented Pyrolytic Graphite, Using X-ray Photoelectron Spectroscopy, J. Phys. Chem. C, 2009, 113(16), 6418-6425.

94 G. S. Tien-Chih Lin and J. A. Kelber, A consistent method for quantitative XPS peak analysis of thin oxide films on clean polycrystalline iron surfaces, Appl. Surf. Sci., 1997, 119, 83-92.

95 Y. Joseph, W. Ranke and W. Weiss, Water on FeO(111) and $\mathrm{Fe}_{3} \mathrm{O}_{4}(111)$ : adsorption behavior on different surface terminations, J. Phys. Chem. B, 2000, 104(14), 3224-3236.

96 T. Kendelewicz, S. Kaya, J. T. Newberg, H. Bluhm, N. Mulakaluri, W. Moritz, et al., X-ray Photoemission and Density Functional Theory Study of the Interaction of Water Vapor with the $\mathrm{Fe}_{3} \mathrm{O}_{4}(001)$ Surface at Near-Ambient Conditions, J. Phys. Chem. C, 2013, 117(6), 2719-2733.

97 K. F. McCarty, M. Monti, S. Nie, D. A. Siegel, E. Starodub, F. El Gabaly, et al., Oxidation of Magnetite(100) to Hematite Observed by In situ Spectroscopy and Microscopy, J. Phys. Chem. C, 2014, 118(34), 19768-19777.

98 E. Paparazzo, On the quantitative XPS analysis of $\mathrm{Fe}_{2} \mathrm{O}_{3}$ and $\mathrm{Fe}_{1-x} \mathrm{O}$ oxides, J. Electron Spectrosc. Relat. Phenom., 2006, 154(1-2), 38-40.

99 T. Yamashita and P. Hayes, Effect of curve fitting parameters on quantitative analysis of $\mathrm{Fe}_{0.94} \mathrm{O}$ and $\mathrm{Fe}_{2} \mathrm{O}_{3}$ using XPS, J. Electron Spectrosc. Relat. Phenom., 2006, 152(1-2), 6-11.

100 T. Yamashita and P. Hayes, Reply to Paparazzo, J. Electron Spectrosc. Relat. Phenom., 2006, 154(1-2), 41-42.

101 A. P. Grosvenor, B. A. Kobe, M. C. Biesinger and N. S. McIntyre, Investigation of multiplet splitting of $\mathrm{Fe}$ 
2p XPS spectra and bonding in iron compounds, Surf. Interface Anal., 2004, 36(12), 1564-1574.

102 M. Trought, I. Wentworth, T. Leftwich and K. Perrine, Investigation of selective growth of ALD alumina on functionalized HOPG surfaces, Abstr. Pap. Am. Chem. Soc., 2018, 256.

103 E. Sacher, Asymmetries in Transition Metal XPS Spectra: Metal Nanoparticle Structure, and Interaction with the Graphene-Structured Substrate Surface, Langmuir, 2010, 26(6), 3807-3814.

104 T. C. Lin, G. Seshadri and J. A. Kelber, A consistent method for quantitative XPS peak analysis of thin oxide films on clean polycrystalline iron surfaces, Appl. Surf. Sci., 1997, 119(1-2), 83-92.

105 N. S. Clarke and P. G. Hall, Adsorption of water-vapor by iron-oxides. 2. Water isotherms and X-ray photoelectronspectroscopy, Langmuir, 1991, 7(4), 678-682.
106 N. S. McIntyre and D. G. Zetaruk, X-ray photoelectron spectroscopic studies of iron-oxides, Anal. Chem., 1977, 49(11), 1521-1529.

107 T. Kendelewicz, P. Liu, C. S. Doyle, G. E. Brown, E. J. Nelson and S. A. Chambers, Reaction of water with the (100) and (111) surfaces of $\mathrm{Fe}_{3} \mathrm{O}_{4}$, Surf. Sci., 2000, 453(1-3), 32-46.

108 P. Liu, T. Kendelewicz, G. E. Brown, E. J. Nelson and S. A. Chambers, Reaction of water vapor with alpha$\mathrm{Al}_{2} \mathrm{O}_{3}(0001)$ and alpha- $\mathrm{Fe}_{2} \mathrm{O}_{3}(0001)$ surfaces: synchrotron $\mathrm{X}$-ray photoemission studies and thermodynamic calculations, Surf. Sci., 1998, 417(1), 53-65.

109 D. R. Lide, in CRC Handbook of Chemistry and Physics, ed. P. Vanýsek, CRC Press, Taylor \& Francis Group Company, Boca Raton, Florida, 85th edn, 2005, pp. 23-28.

$110 \mathrm{H}$. Augaam, The transformation of lepidocrocite during heating: a magnetic and spectroscopic study, Clays Clay Miner., 1994, 42, 409-415. 